\title{
INDIVIDUAL RESULTS OF OBSERVATIONS
}

\author{
EPOCH 1900.0
}

REDUCED TO A LATITUDE OF + $38^{\circ} 55^{\prime} 14.61^{\prime \prime}$

A 1 


\section{INDIVIDUAL RESULTS OF OBSERVATIONS}

\section{EPOCH, 1900.0}

REDUCED TO A LATITUDE OF $+38^{\circ} 55^{\prime} 14.61^{\prime \prime}$

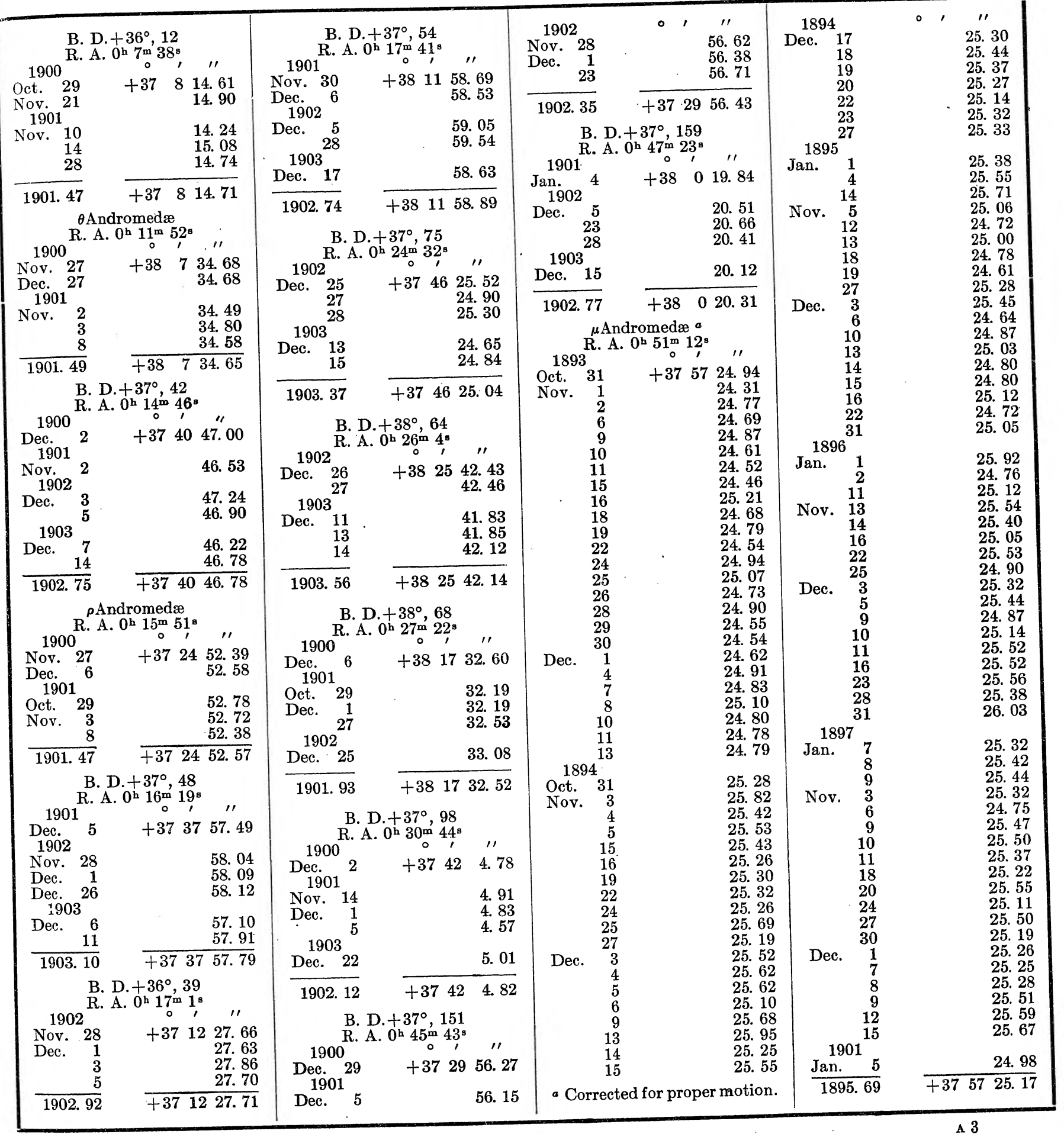




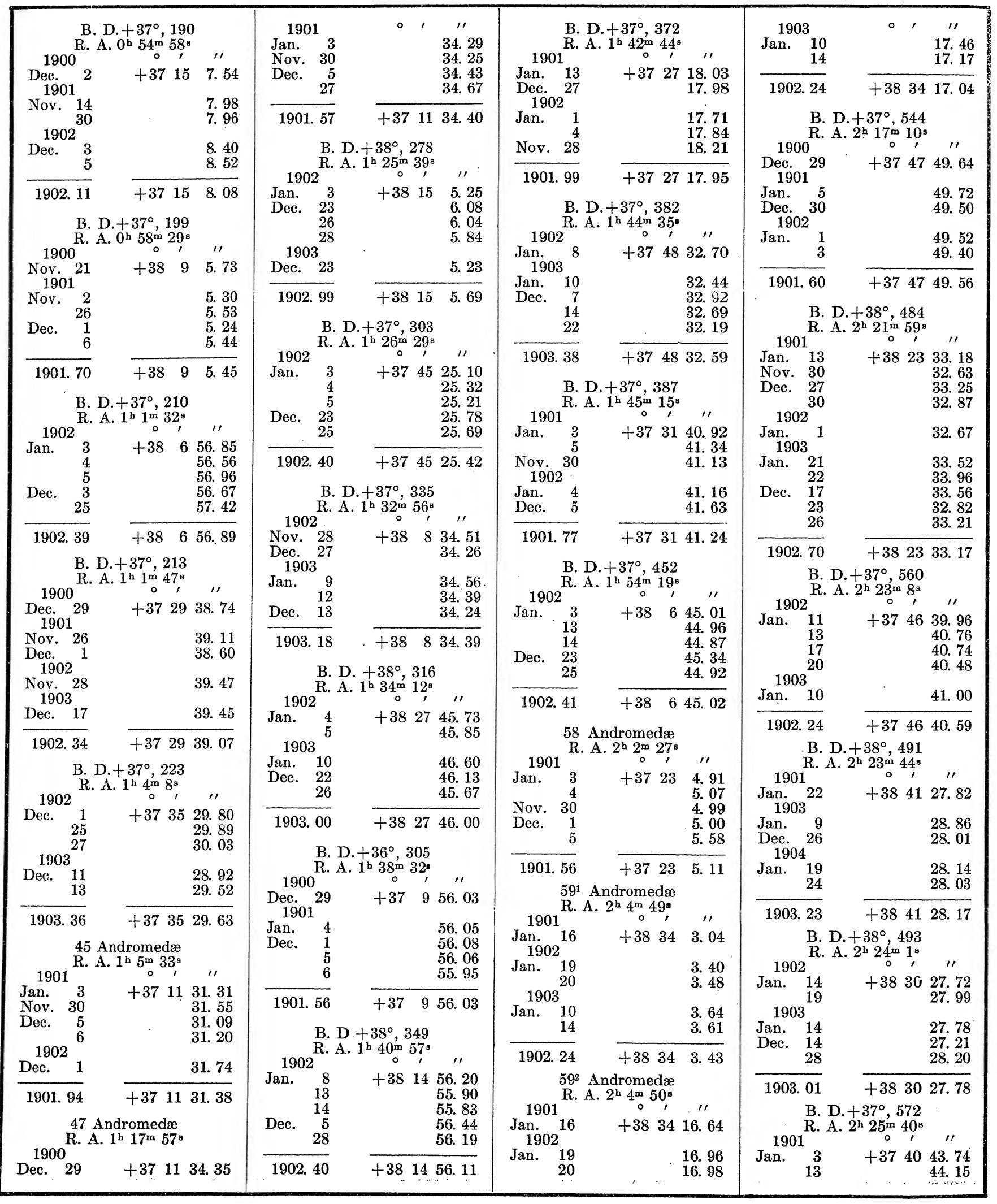




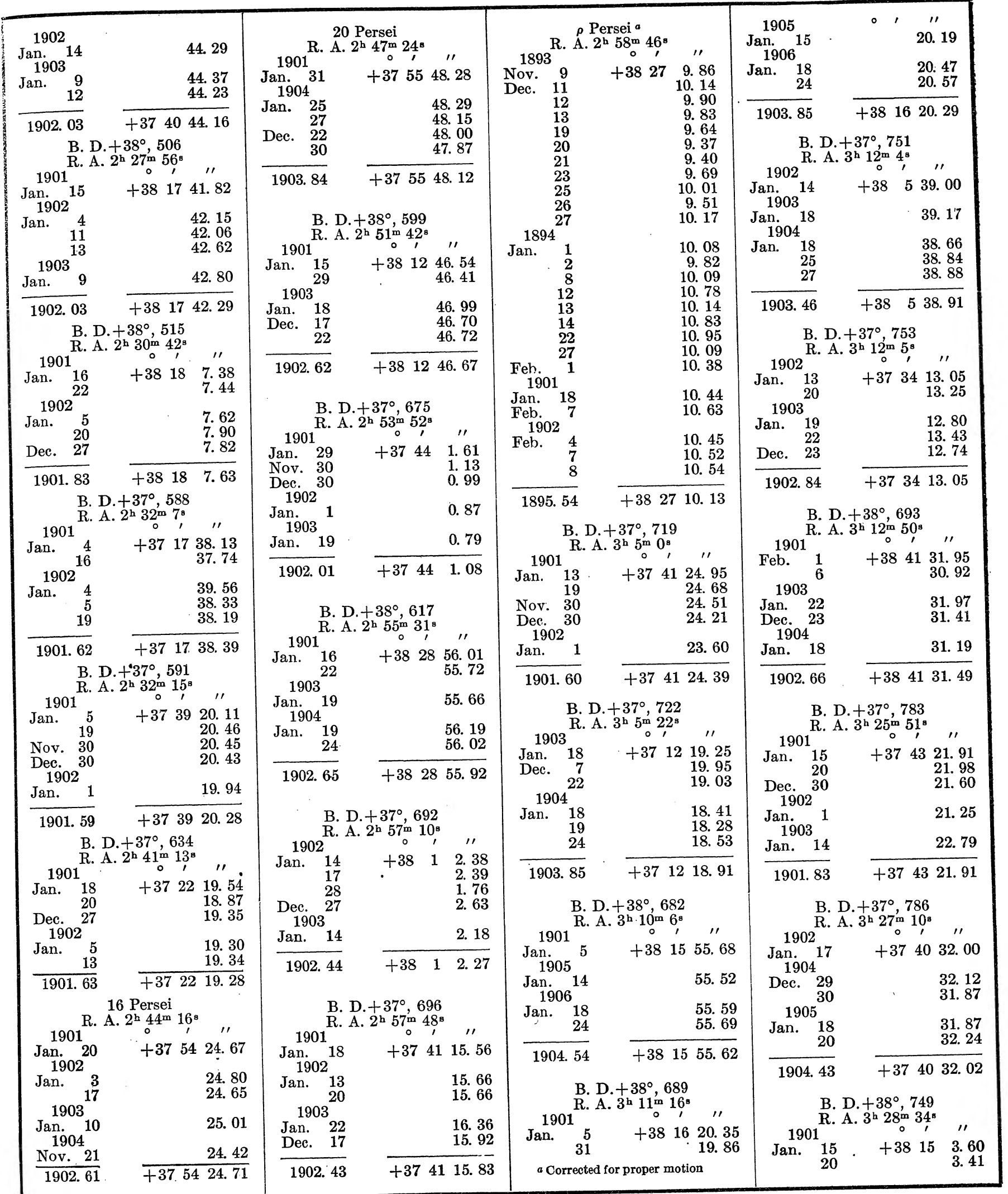




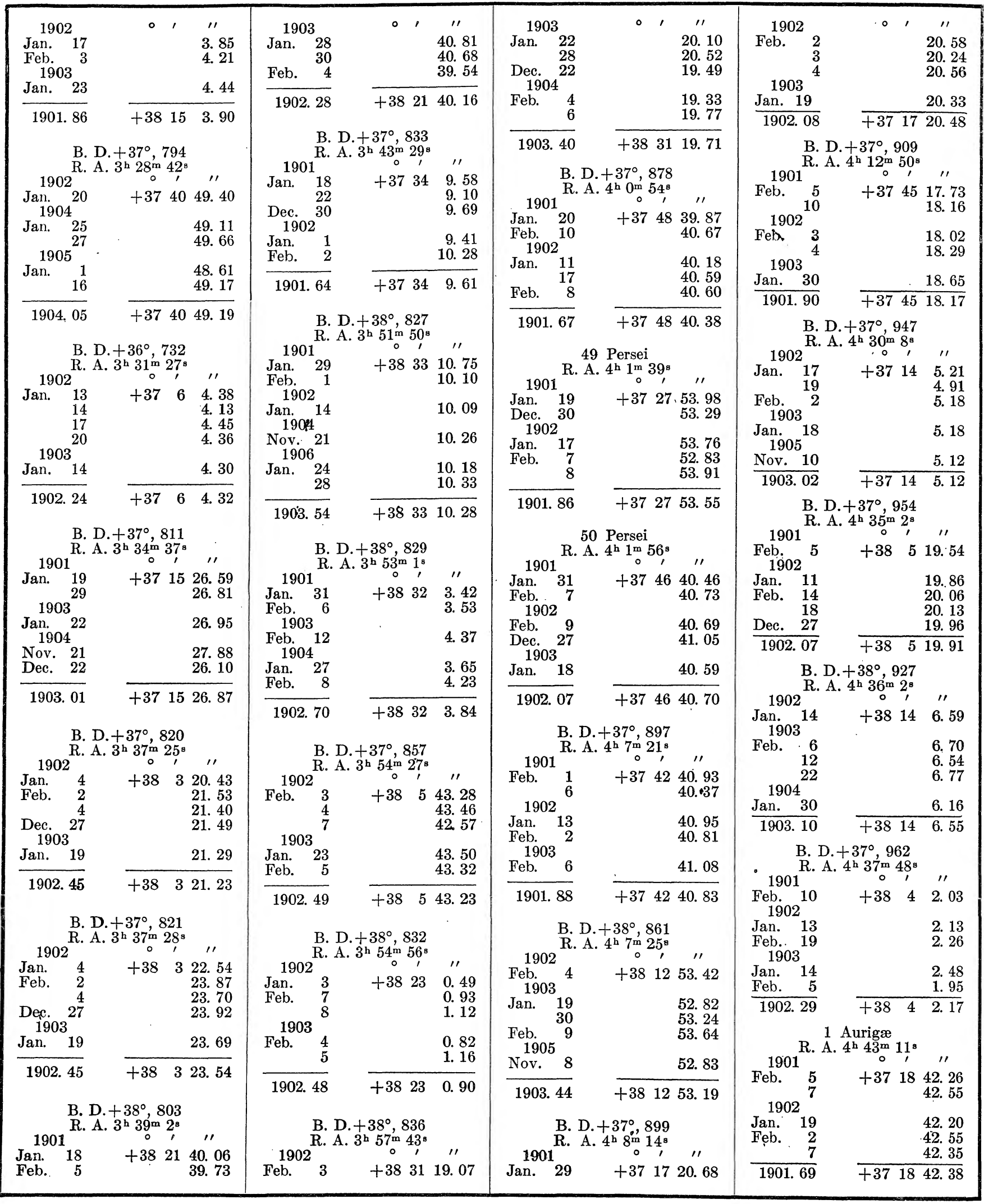




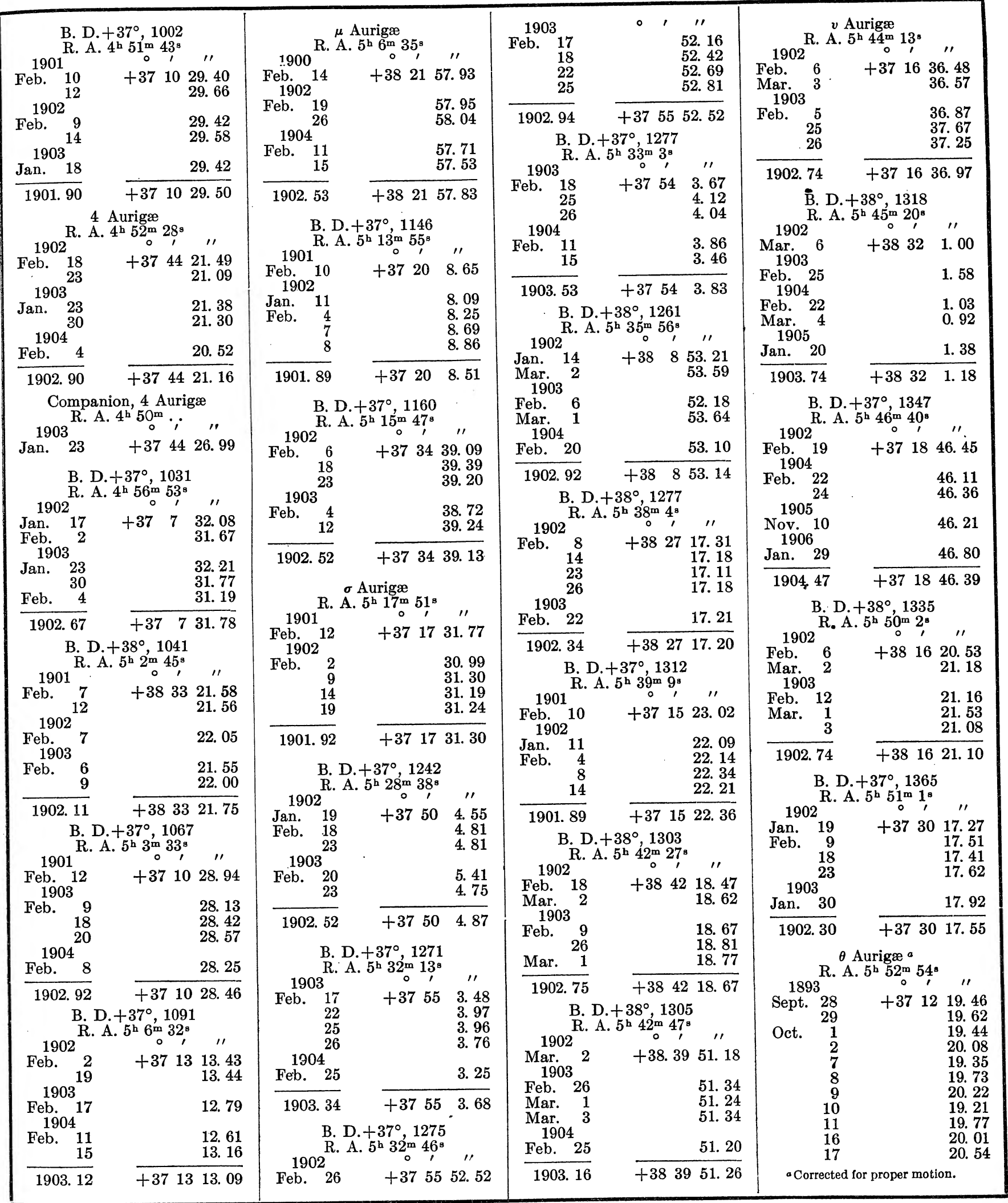

$101141^{\circ}-26 \dagger-\mathrm{PT} \mathrm{I} \longrightarrow 15$ 


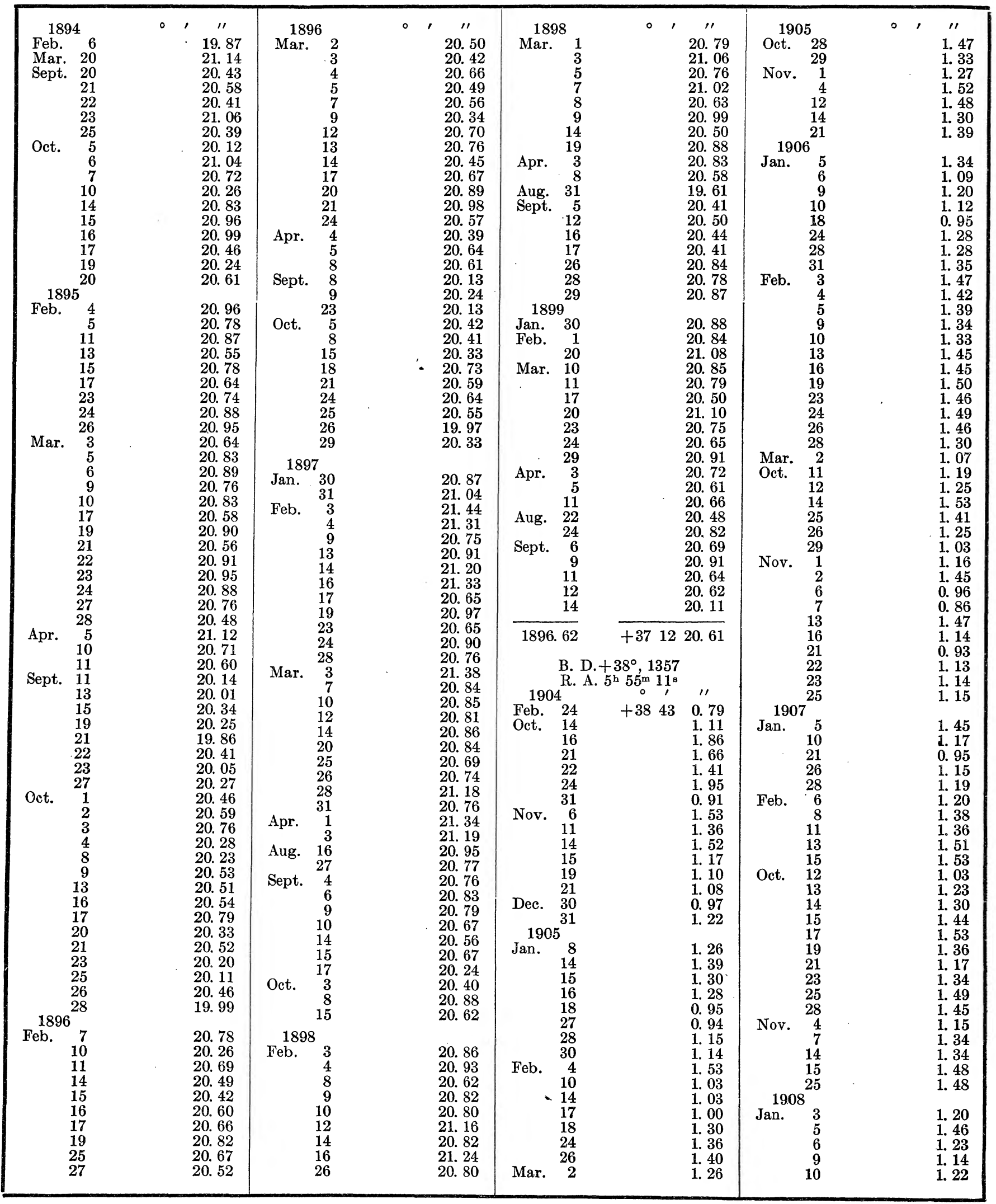


INDIVIDUAL RESULTS OF OBSERVATIONS.

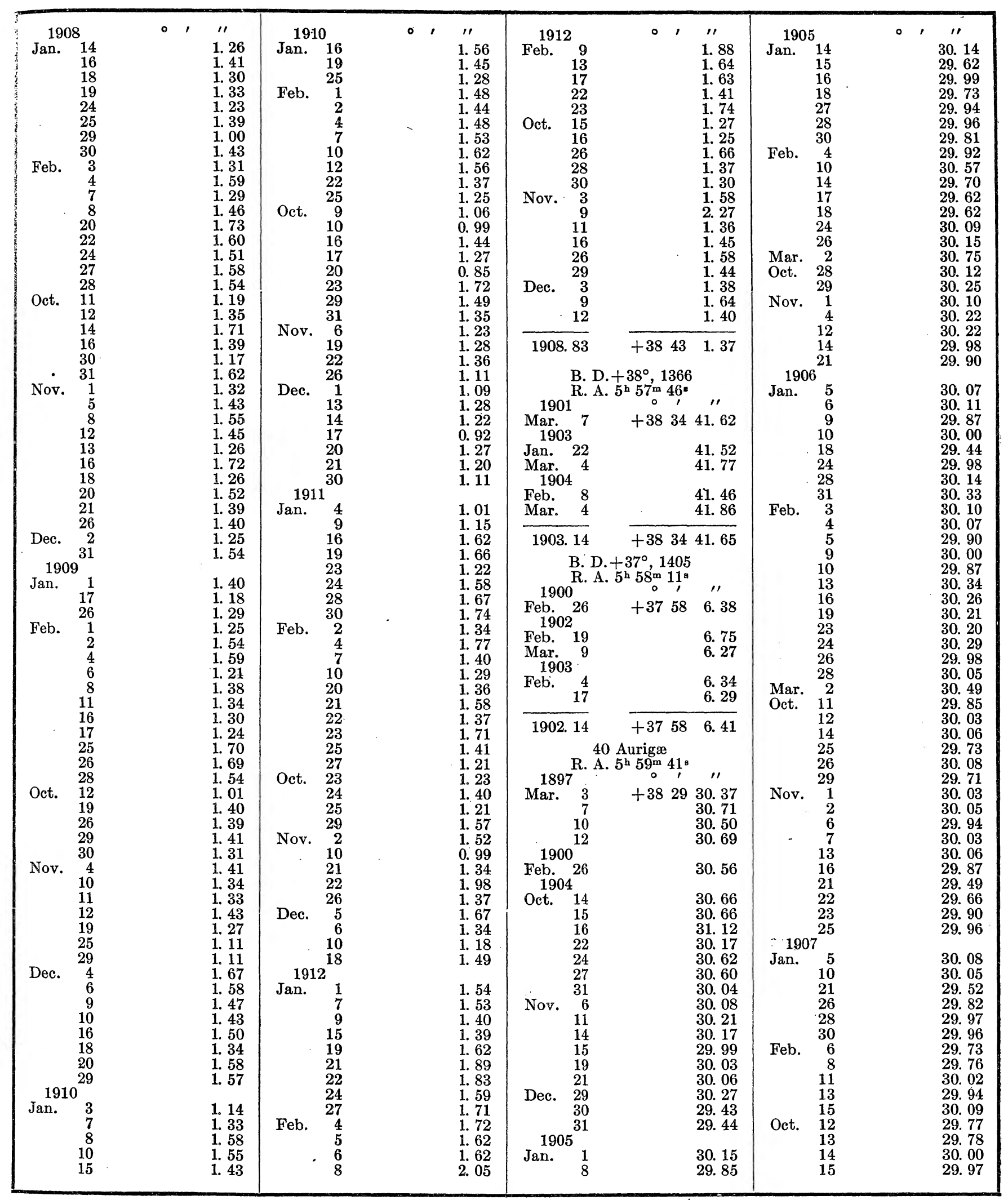




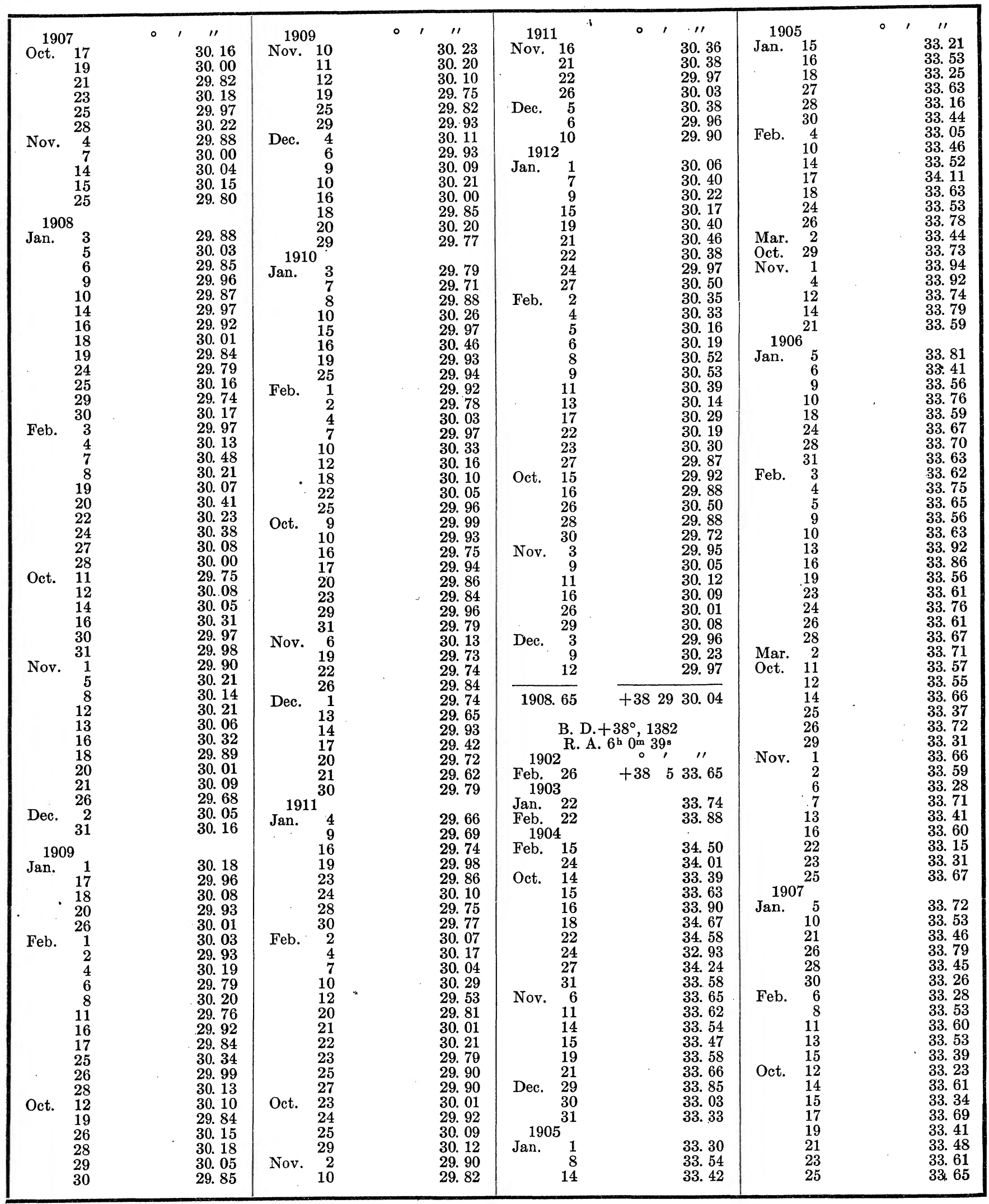




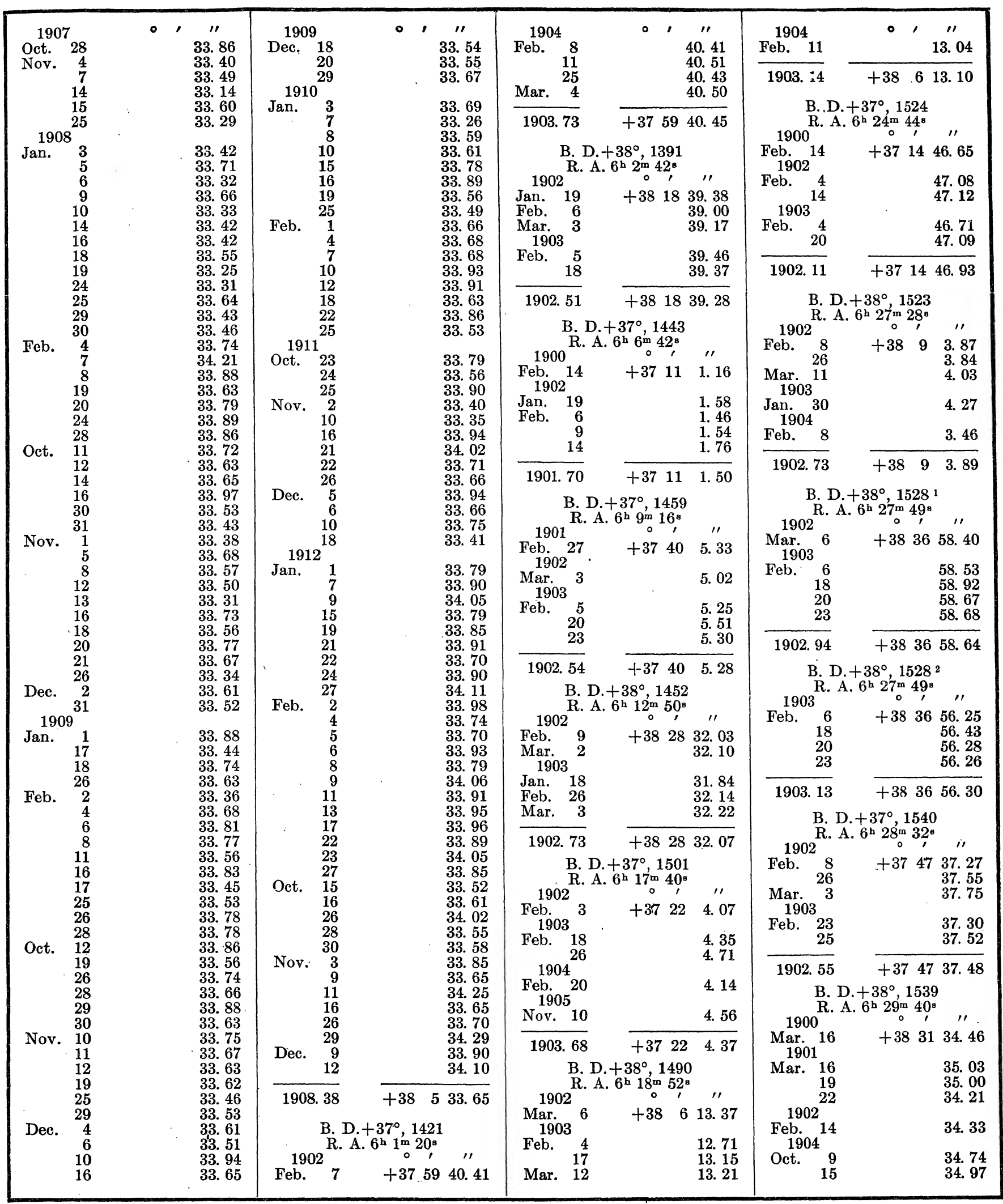




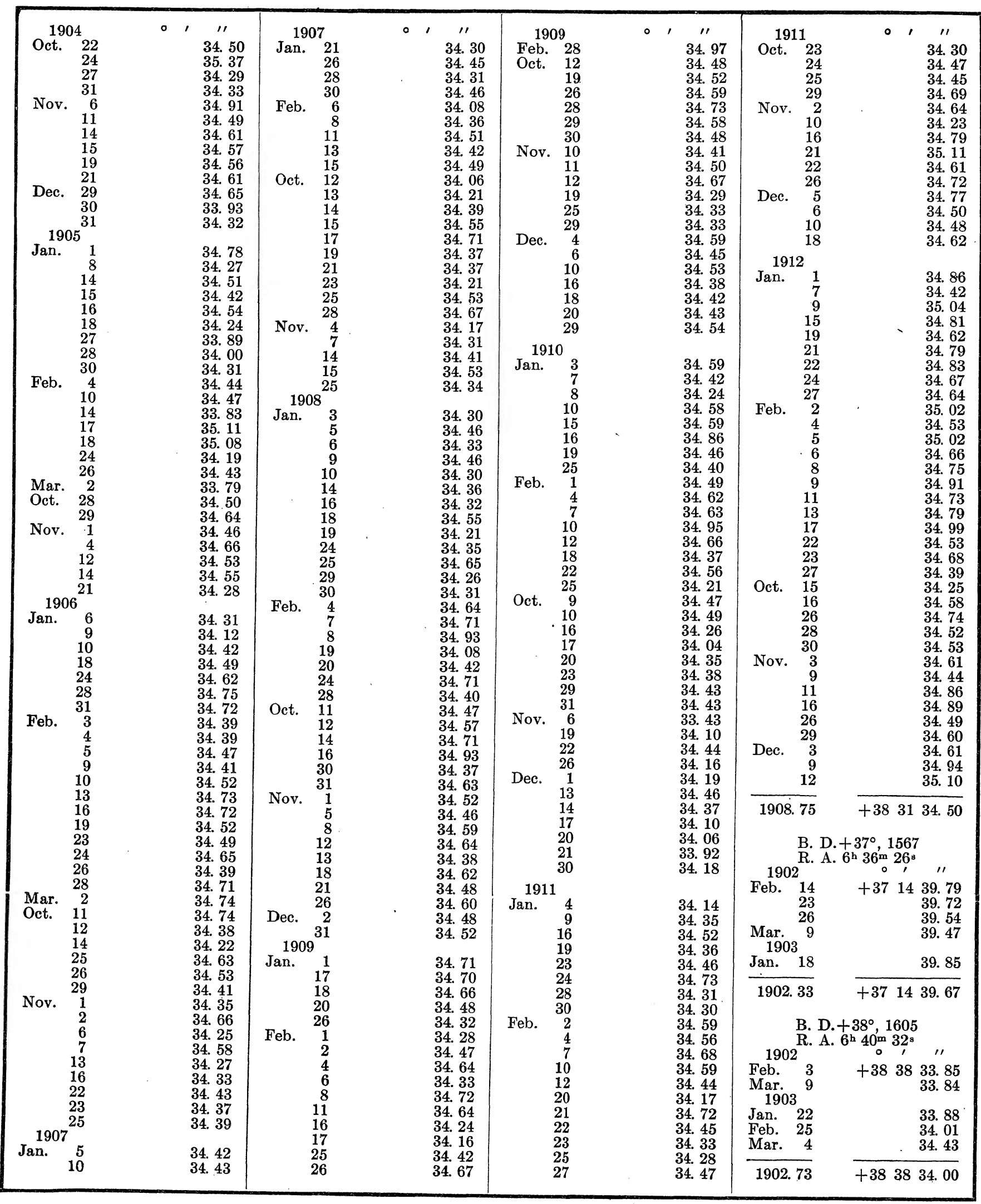




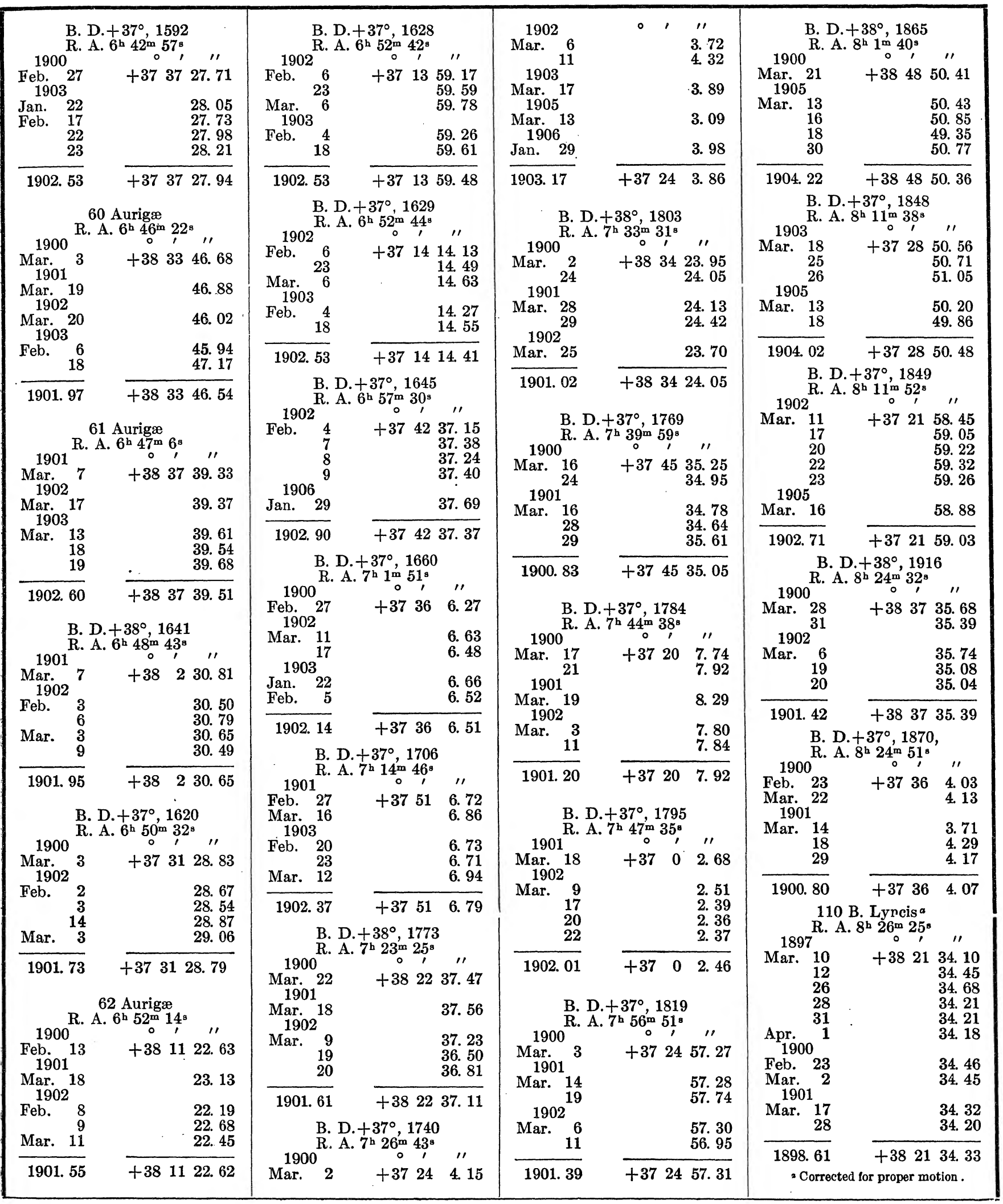




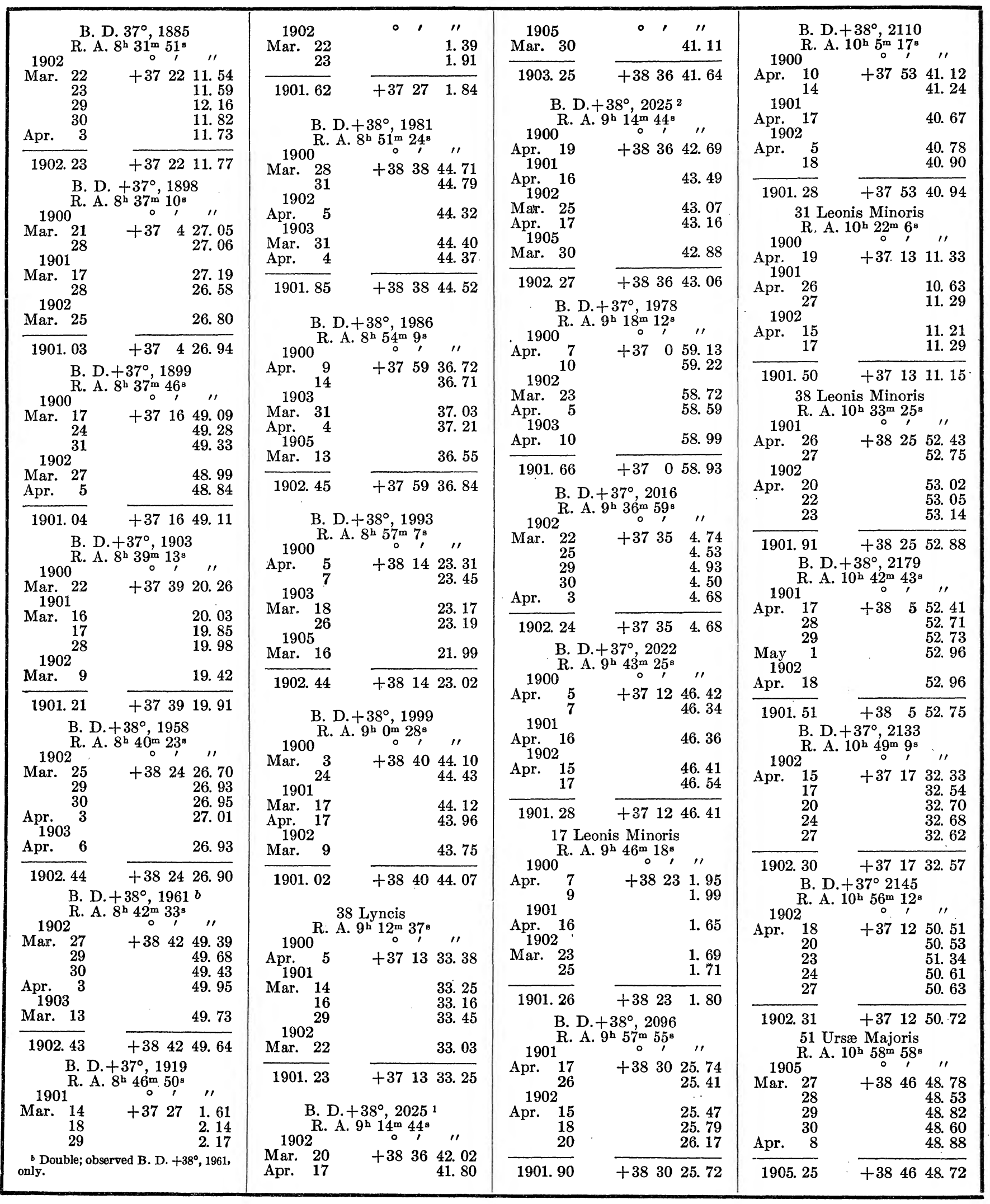




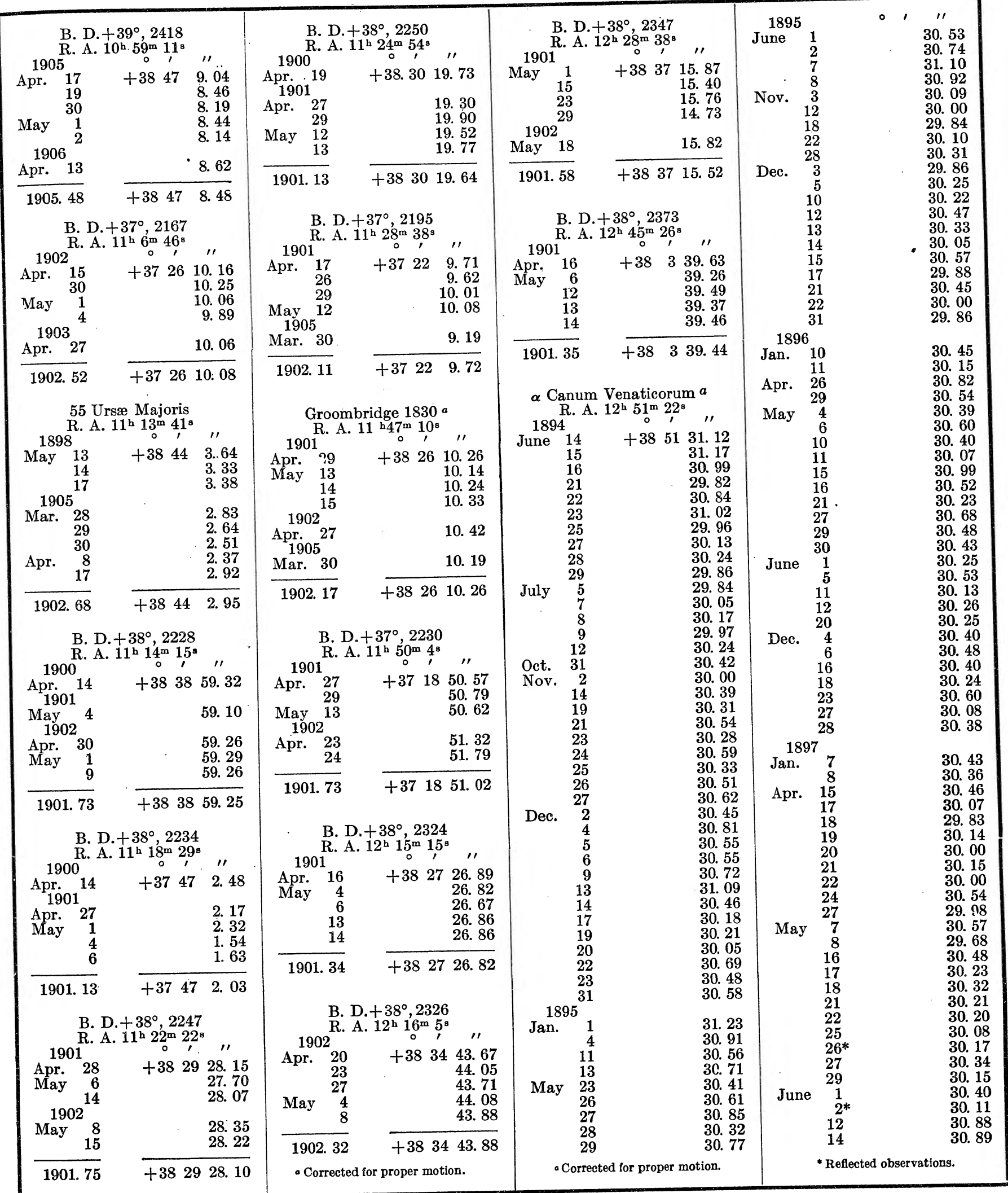




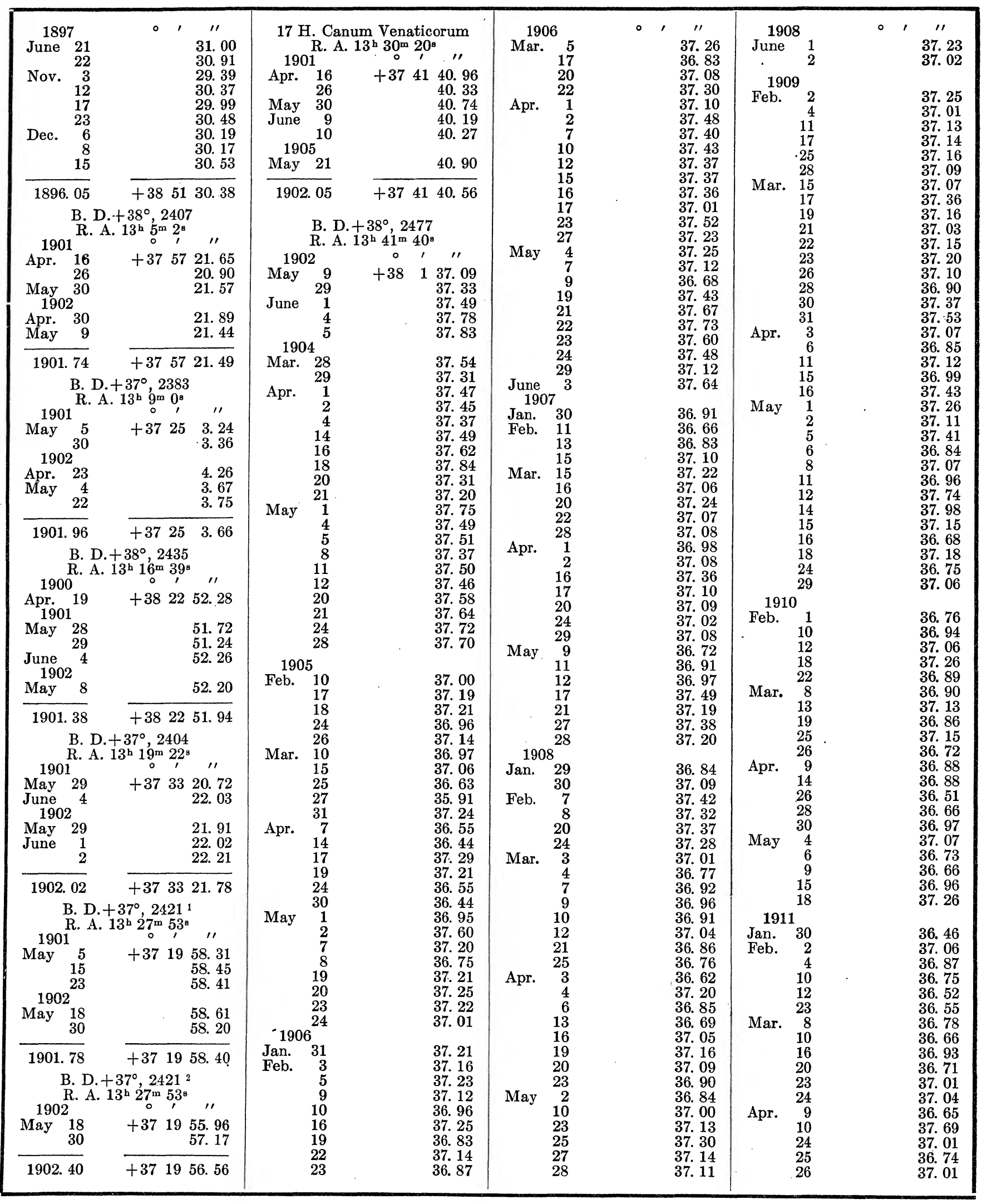




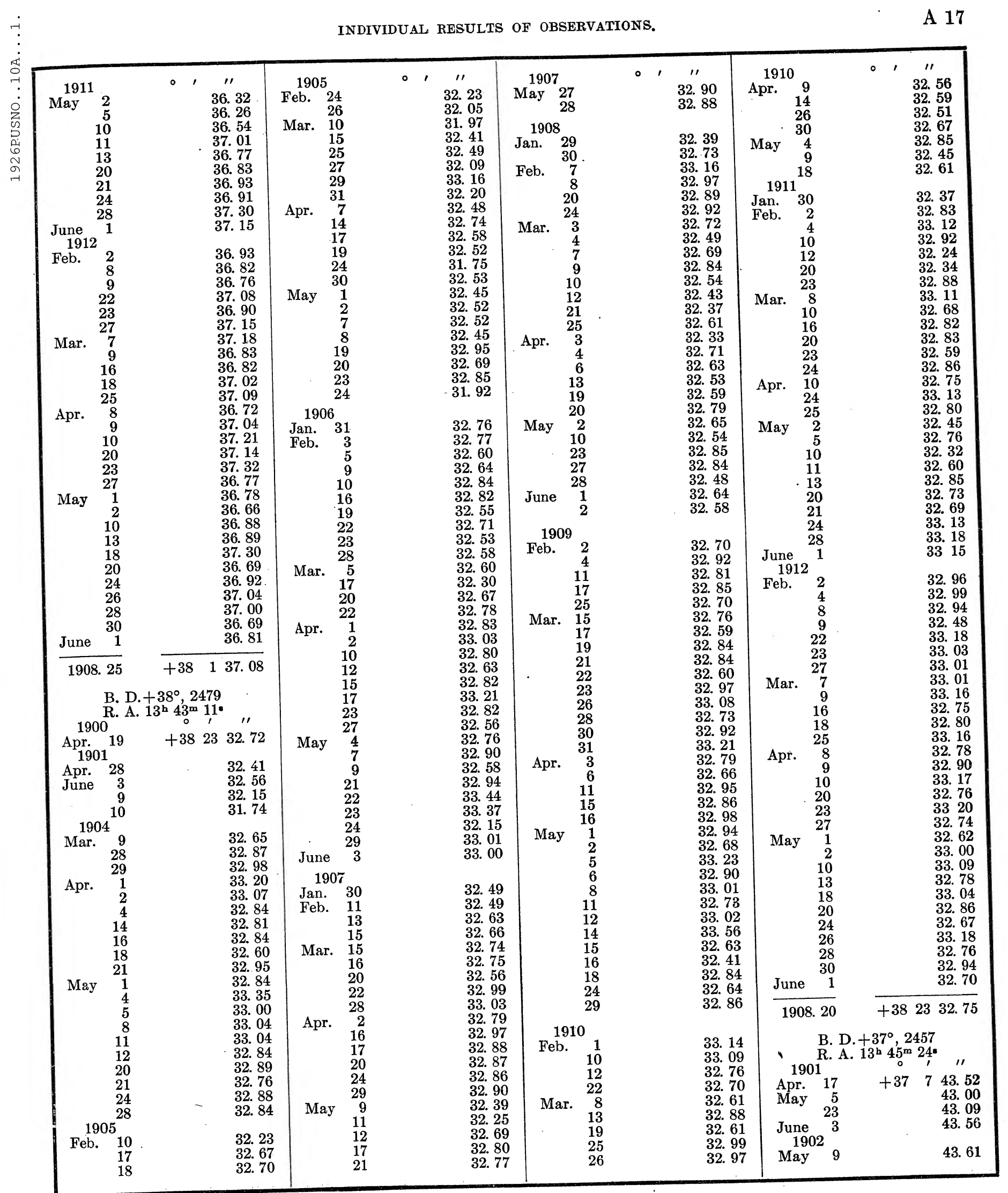




\begin{tabular}{|c|c|c|c|c|c|c|c|c|c|c|c|c|}
\hline 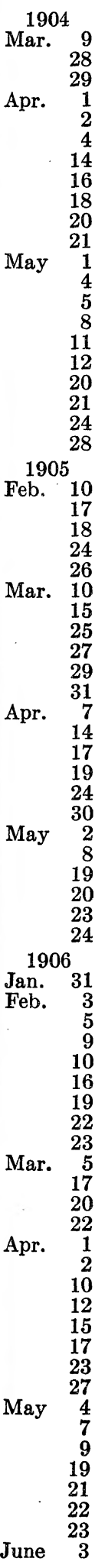 & & $\begin{array}{l}43.75 \\
43.48 \\
43.47 \\
43.47 \\
43.75 \\
43.81 \\
43.52 \\
43.39 \\
43.43 \\
43.73 \\
43.31 \\
43.48 \\
43.97 \\
43.53 \\
44.16 \\
44.11 \\
44.13 \\
43.86 \\
43.16 \\
43.75 \\
43.64 \\
43.61 \\
43.44 \\
43.53 \\
43.42 \\
43.80 \\
43.86 \\
44.04 \\
43.98\end{array}$ & 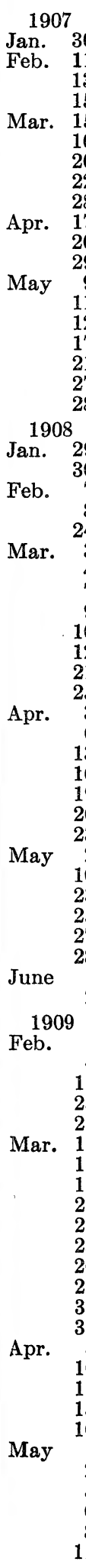 & 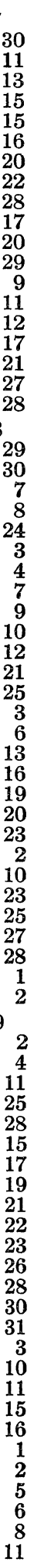 & $\circ$ & 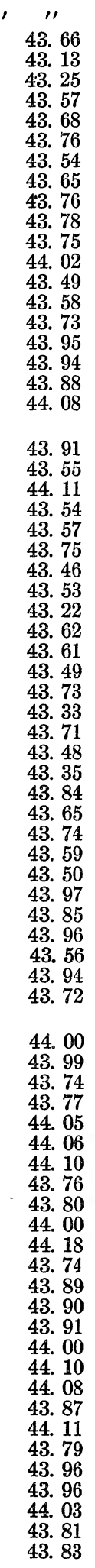 & 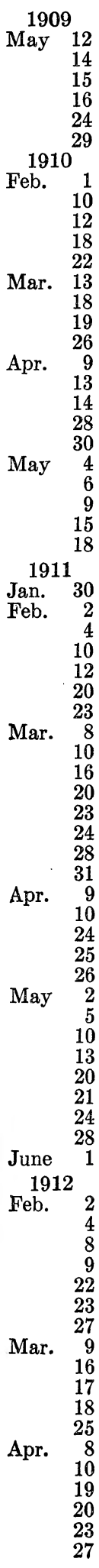 & & $\begin{array}{l}43.45 \\
43.64 \\
43.63 \\
44.08 \\
43.75 \\
43.61 \\
43.84 \\
43.90 \\
44.09 \\
43.82 \\
43.53 \\
43.81 \\
44.20 \\
43.92 \\
44.07 \\
44.00 \\
43.65 \\
44.24 \\
43.70 \\
43.82 \\
43.86 \\
43.26 \\
43.72 \\
43.83 \\
43.74 \\
43.92 \\
43.66 \\
44.40 \\
44.08\end{array}$ & 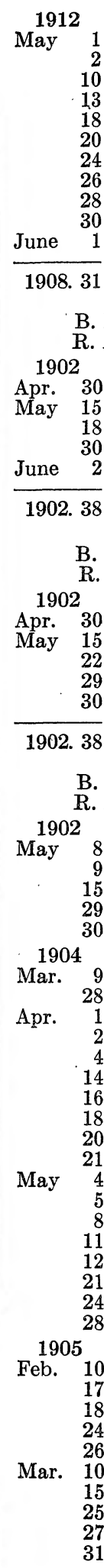 & 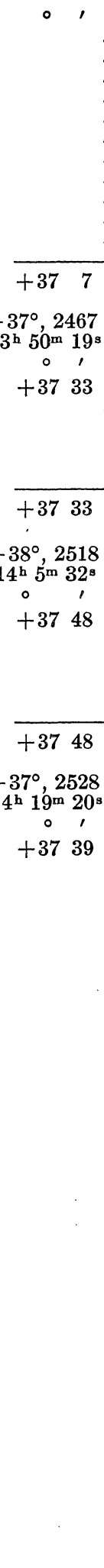 & 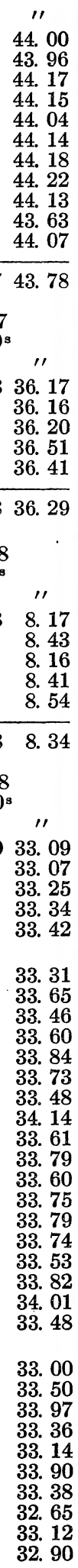 \\
\hline
\end{tabular}




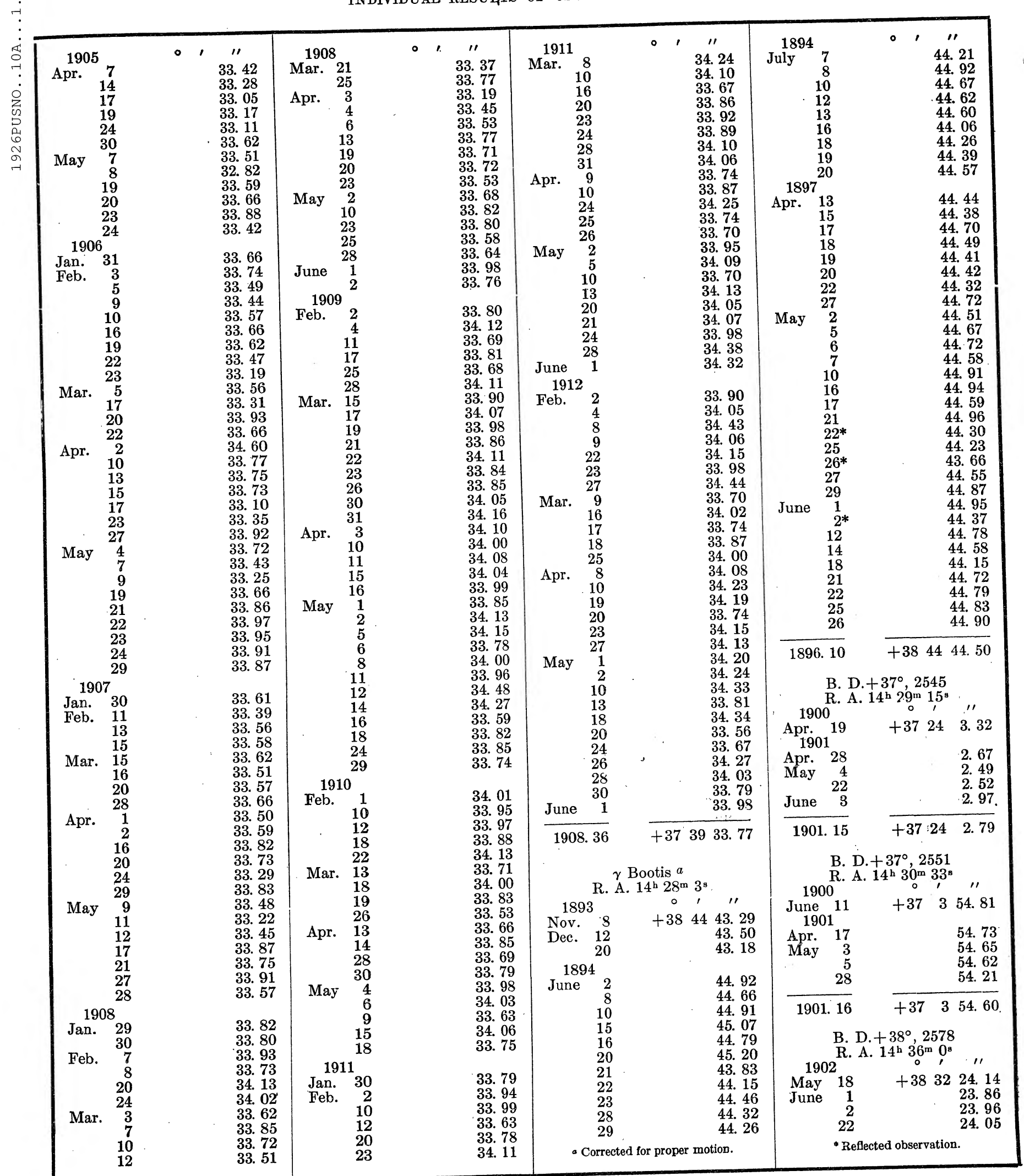




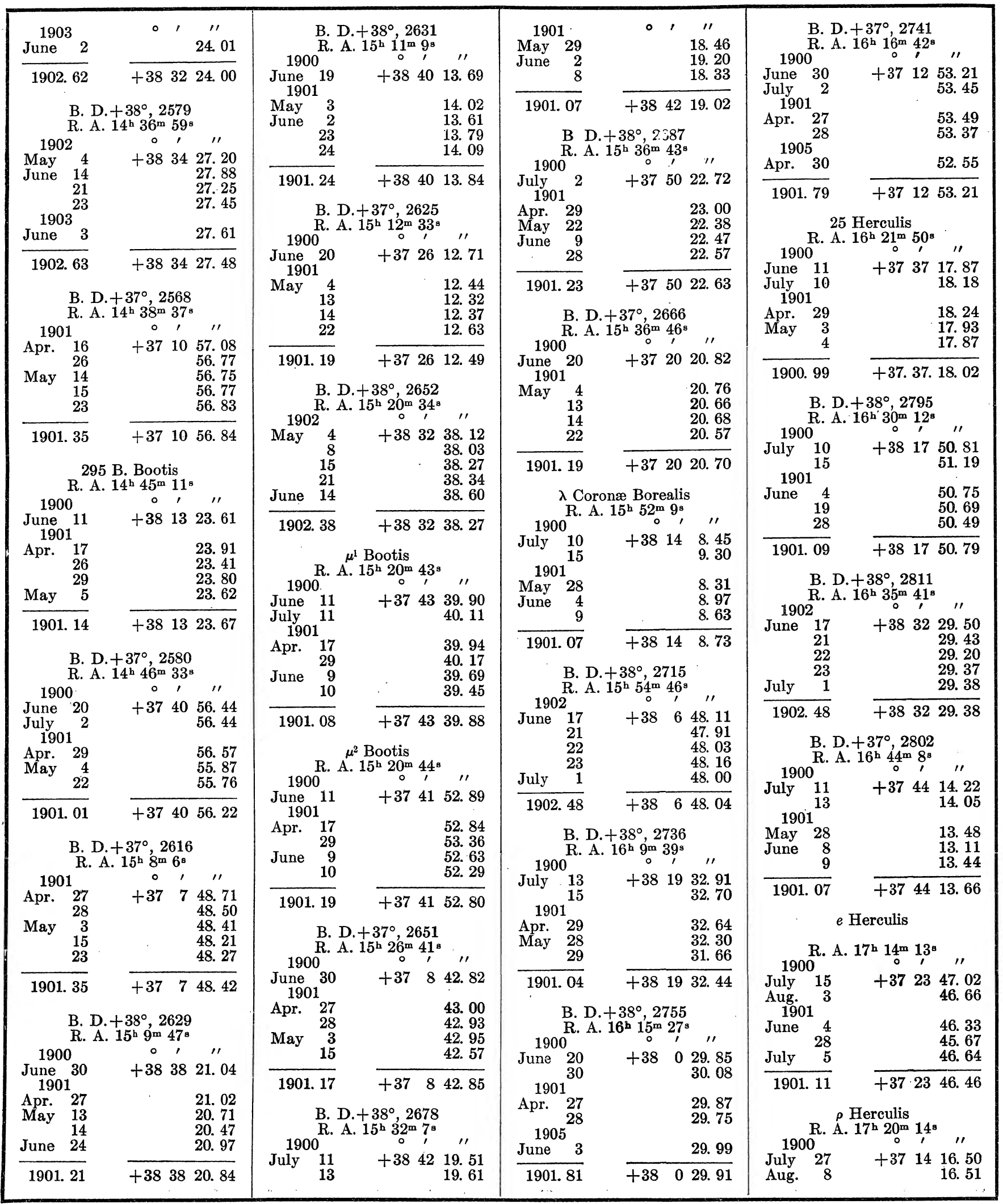


INDIVIDUAL RESULTS OF OBSERVATIONS.

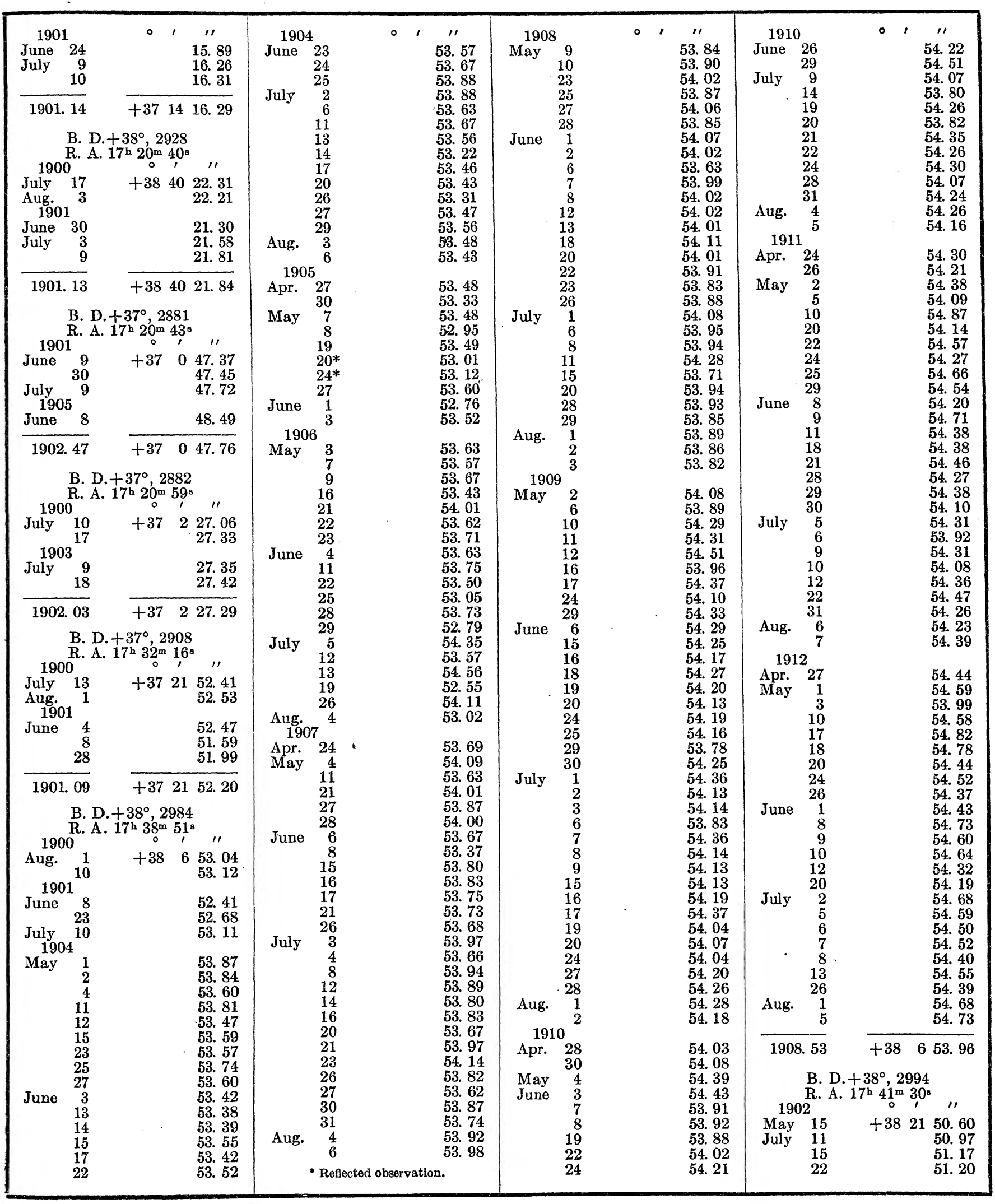




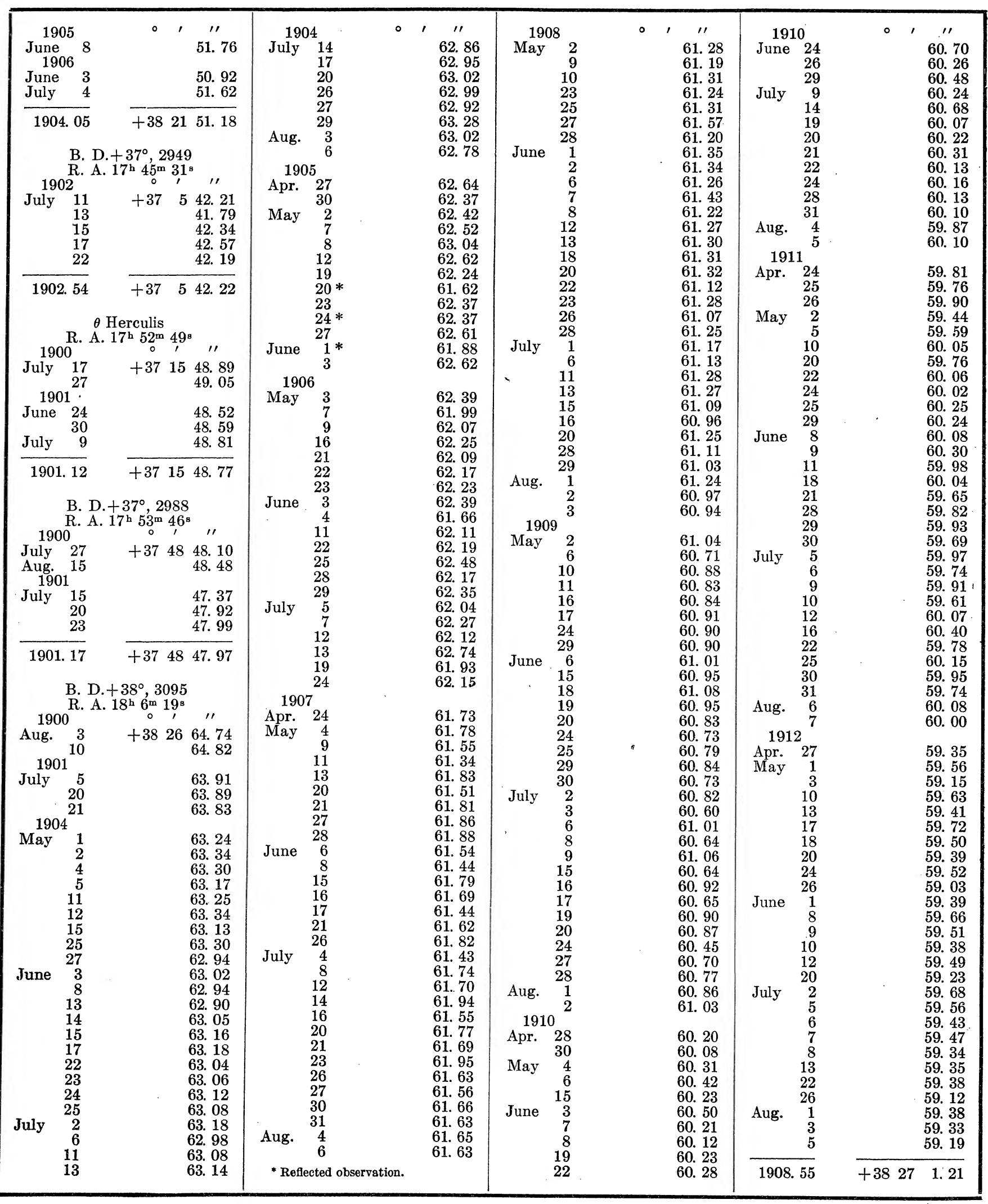




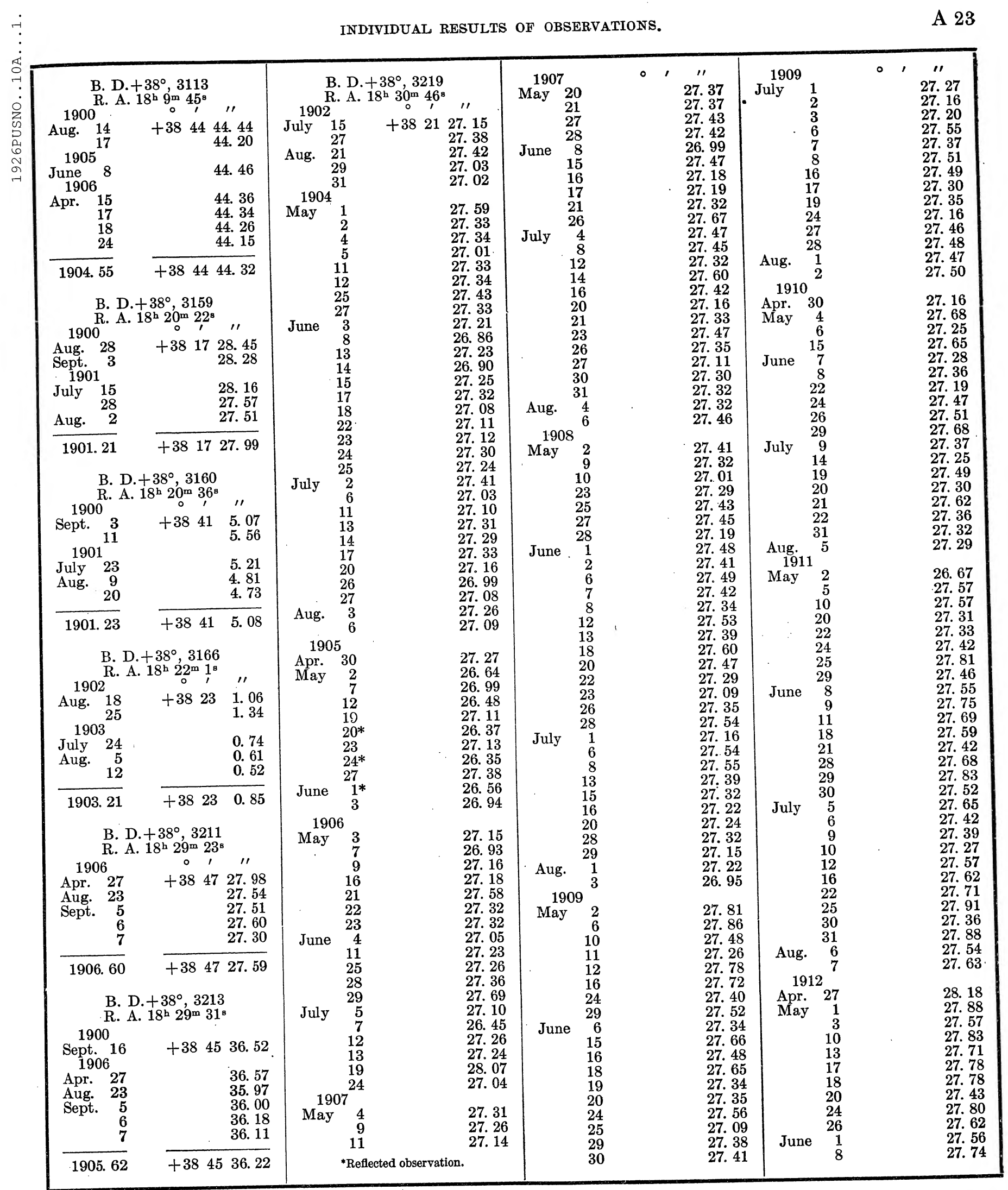

$101141^{\circ}-26 \dagger-\mathrm{PT} \mathrm{I}-16$ 


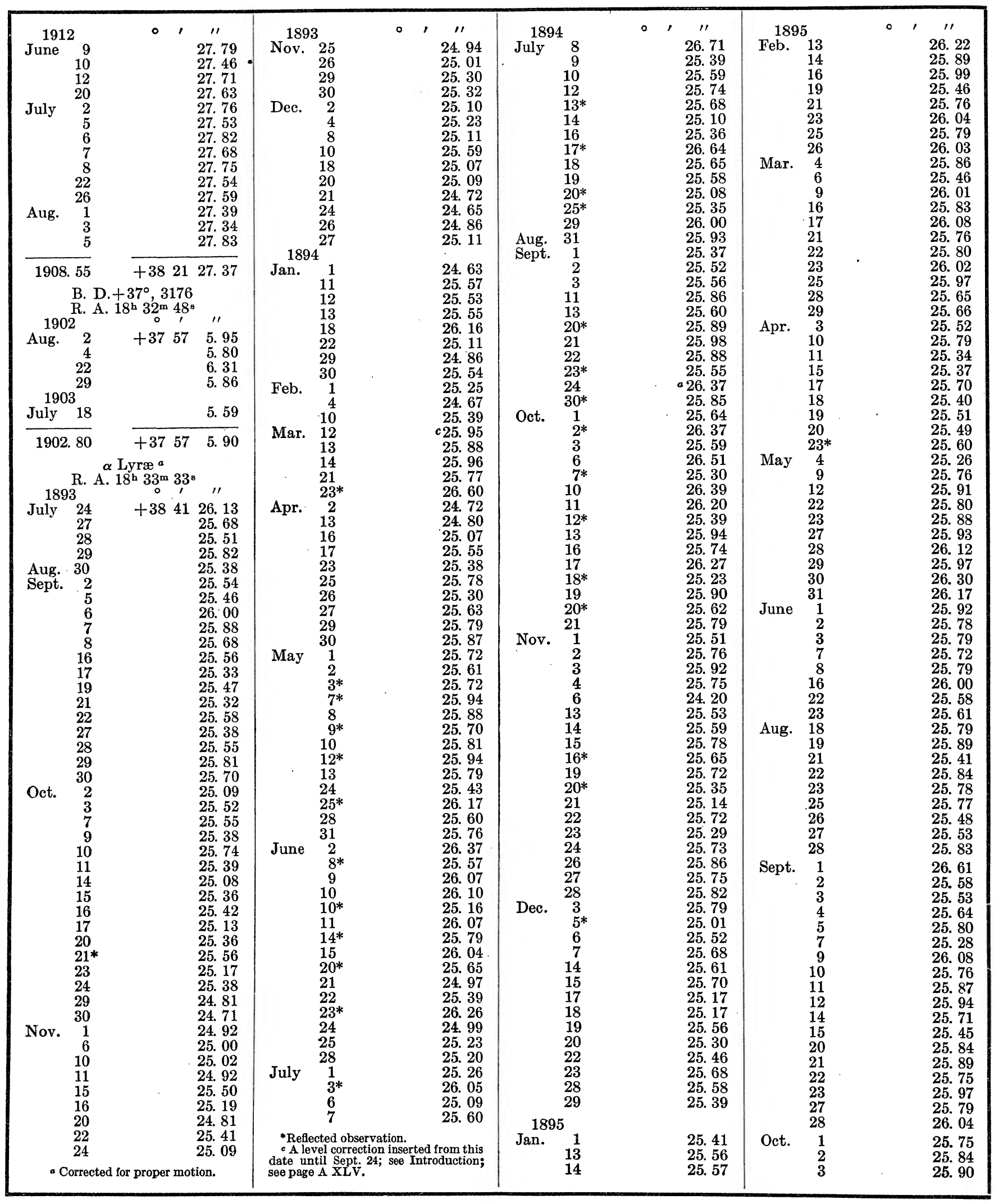




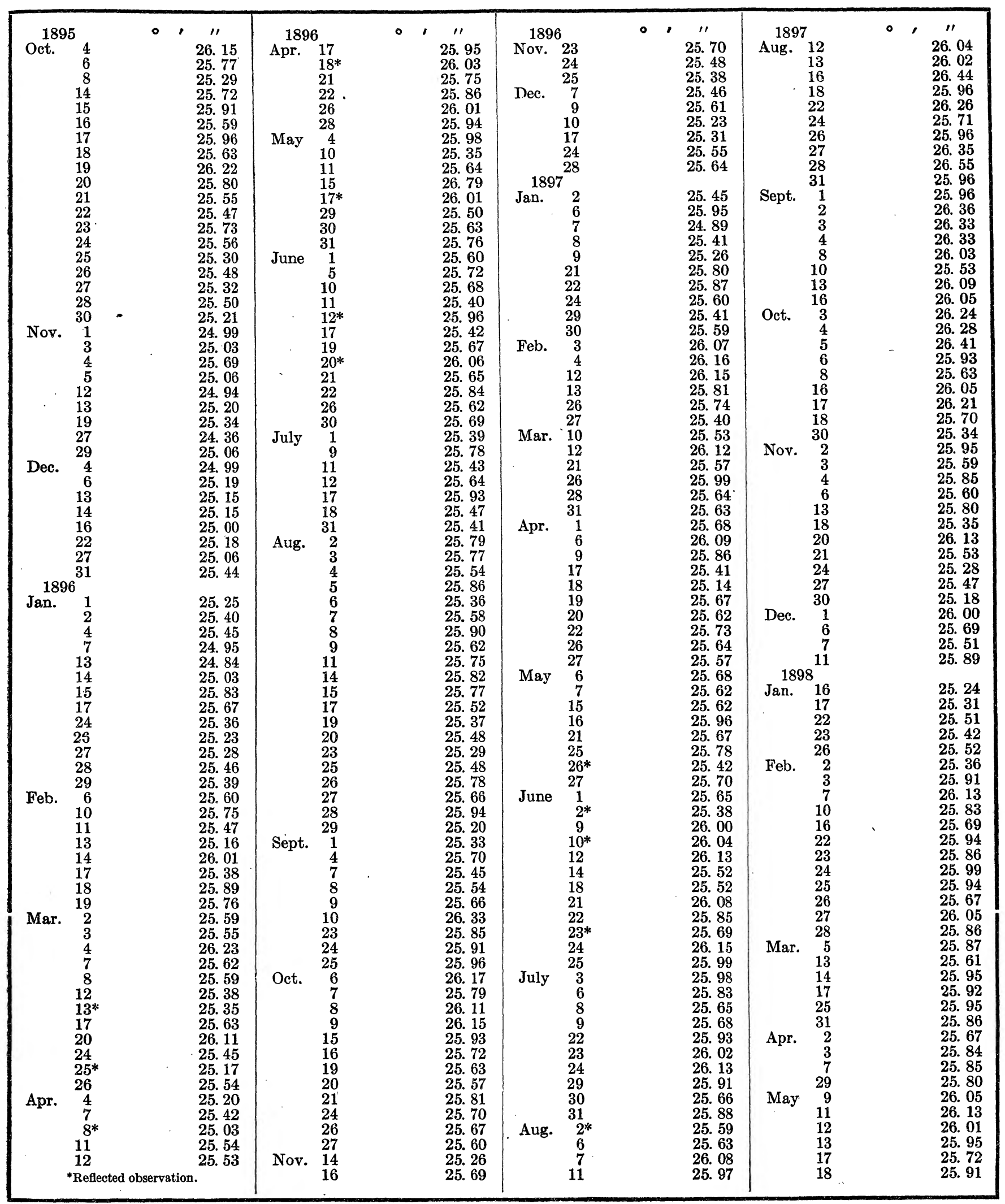




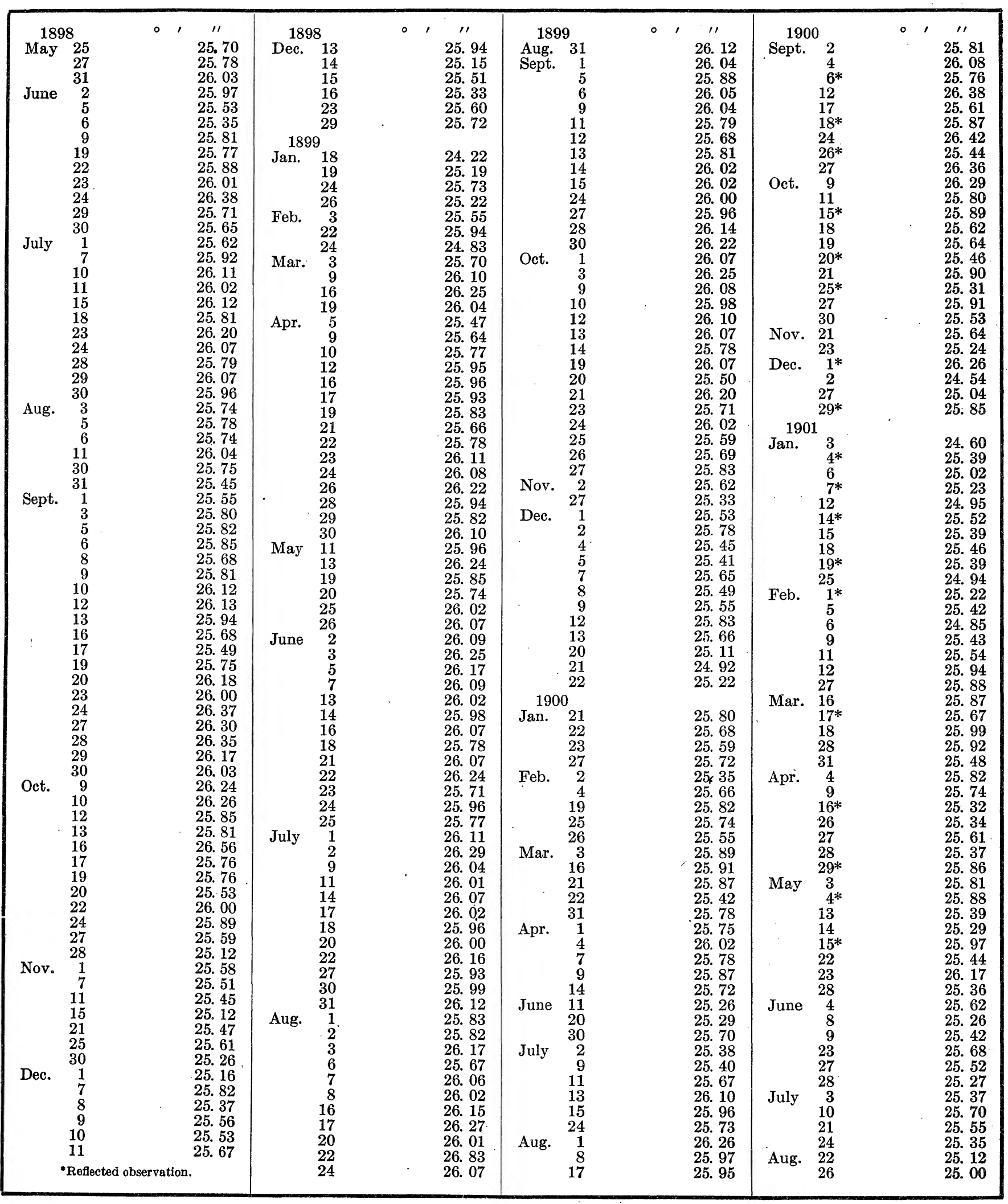




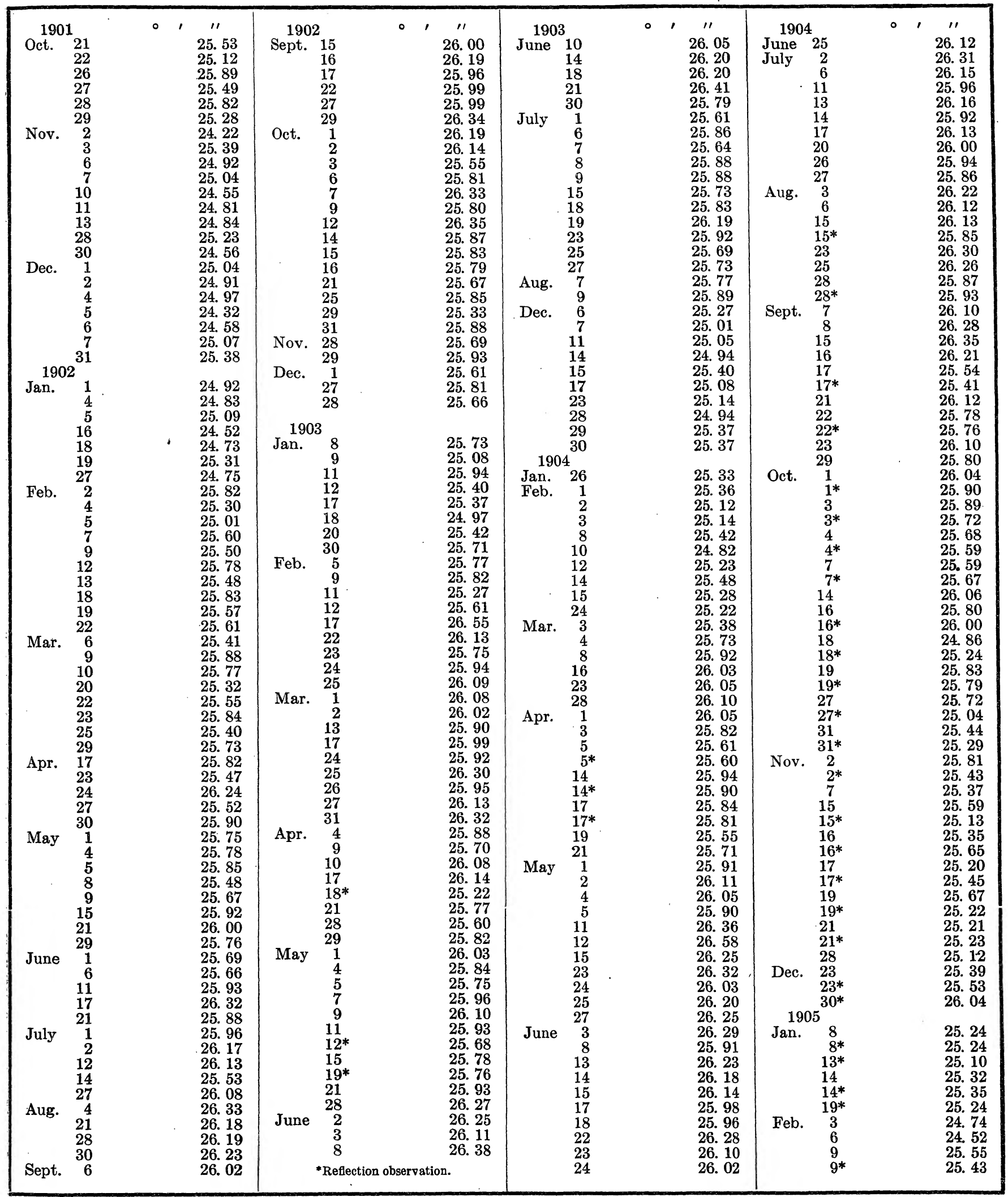




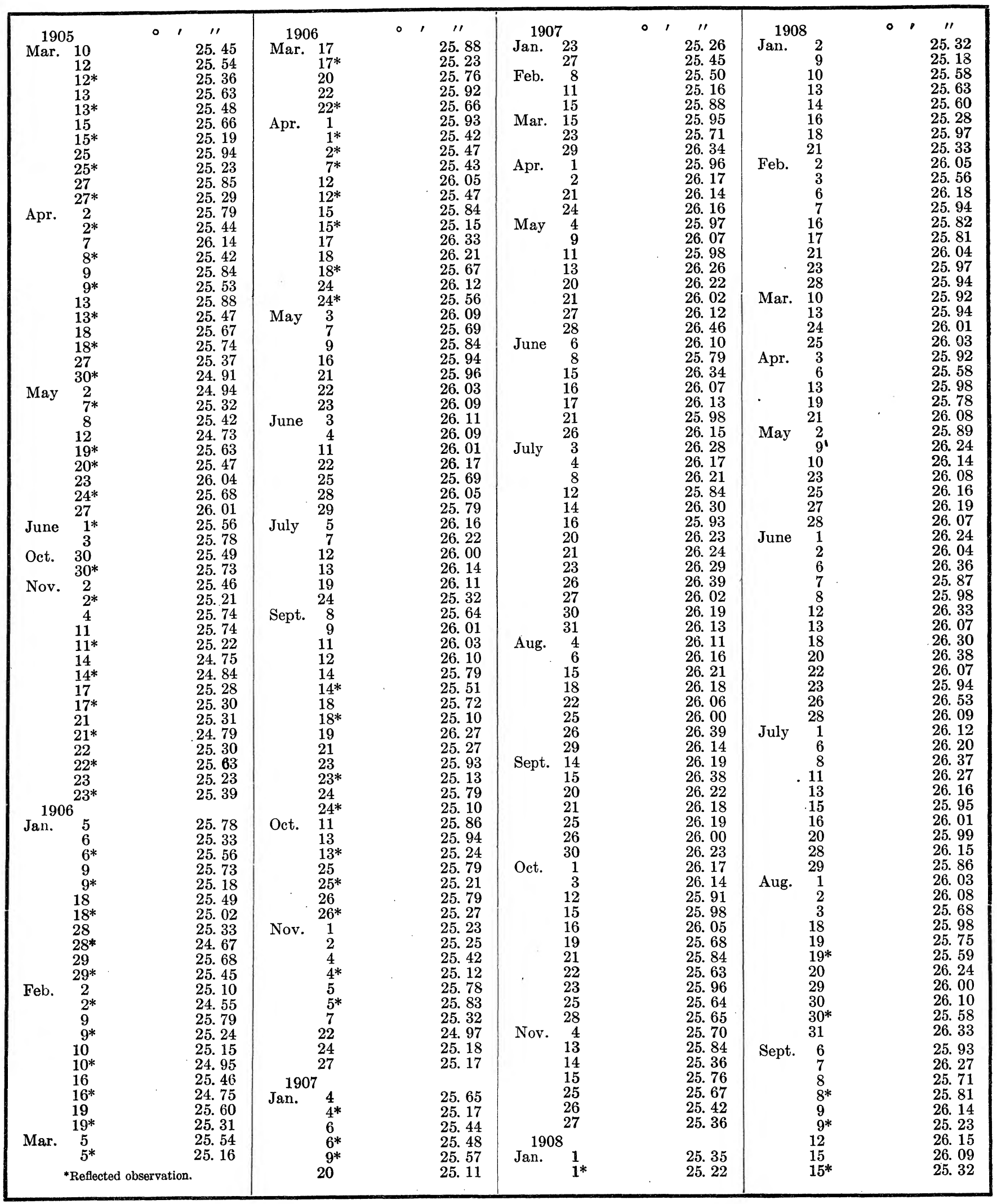




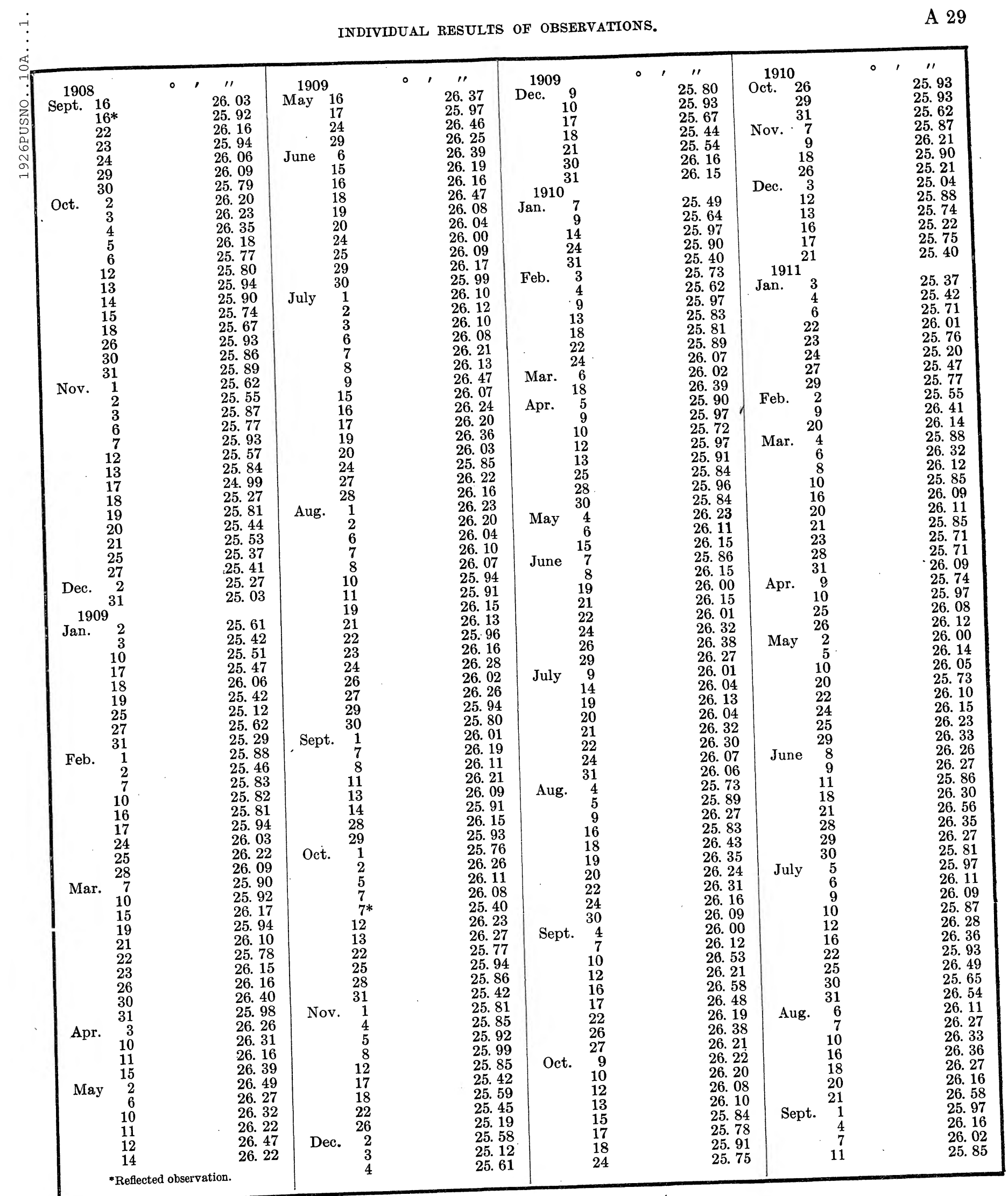




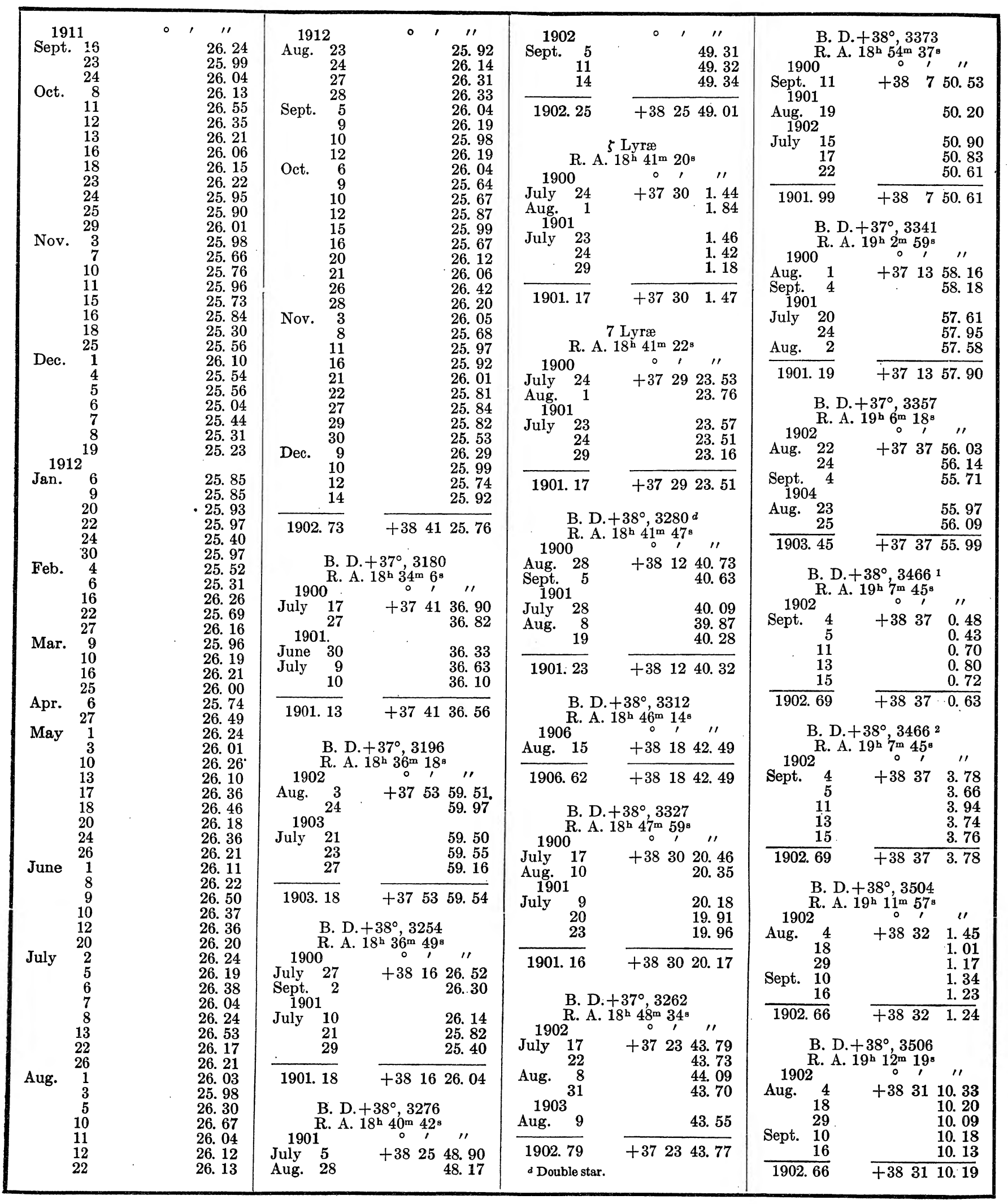




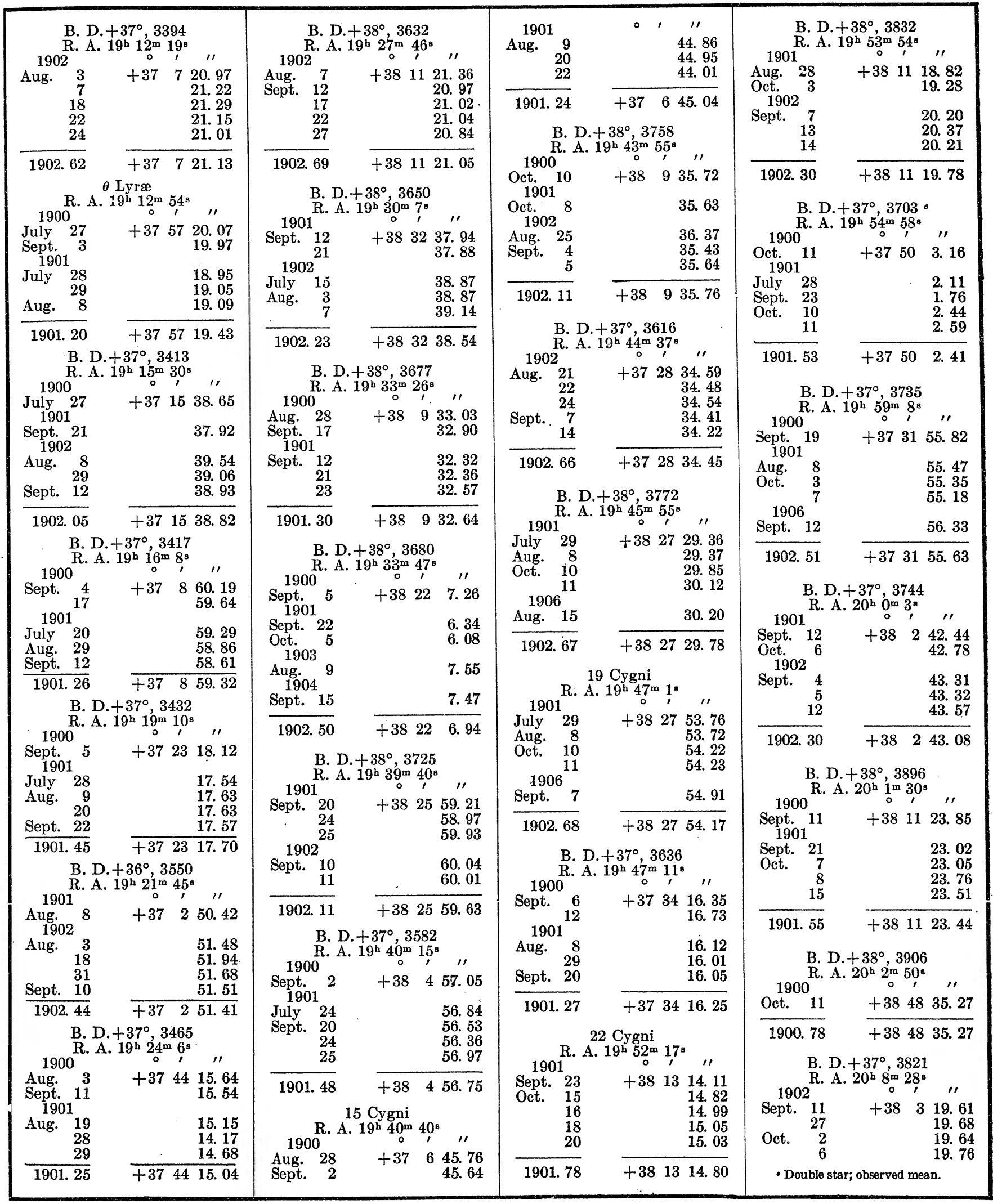









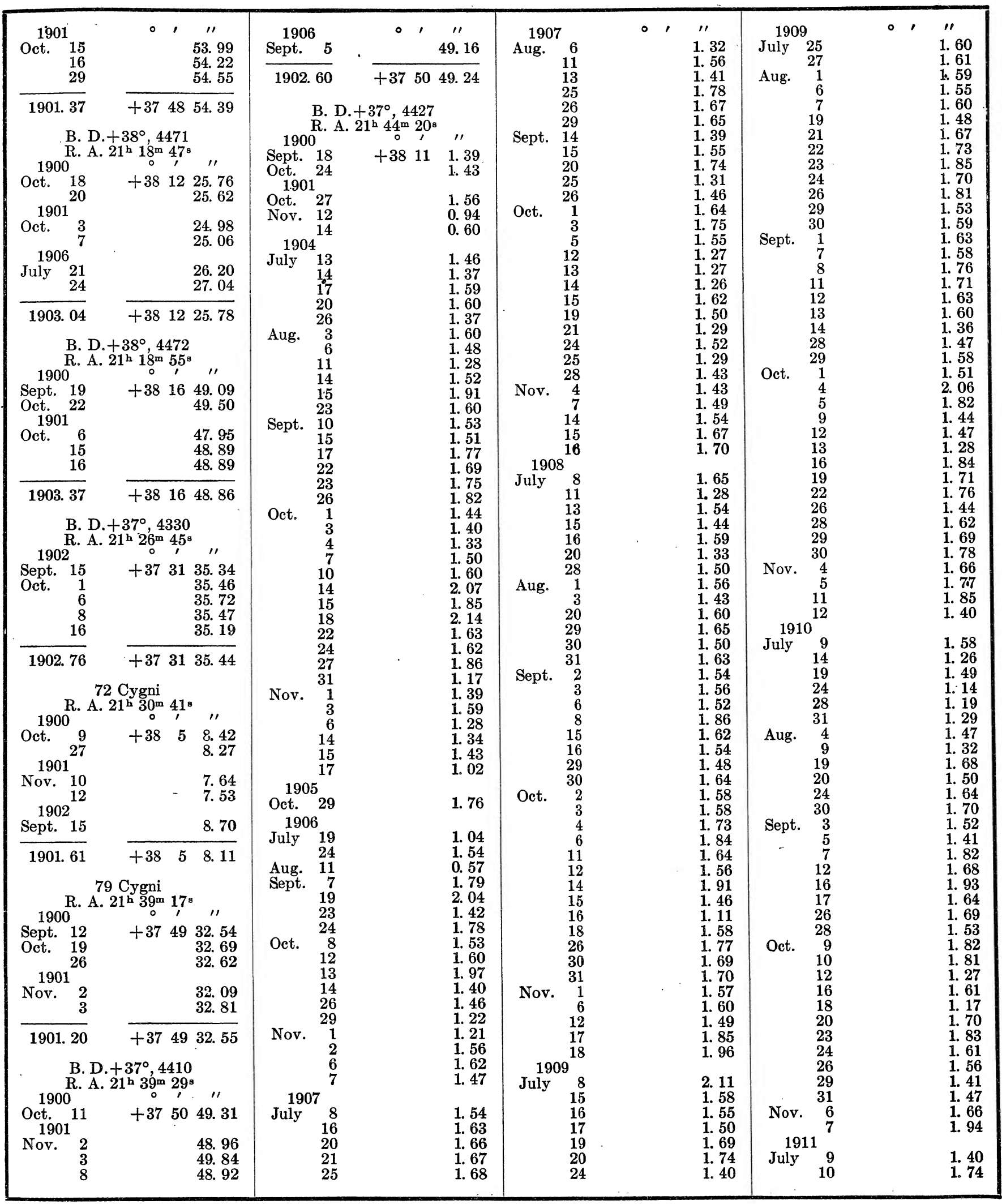




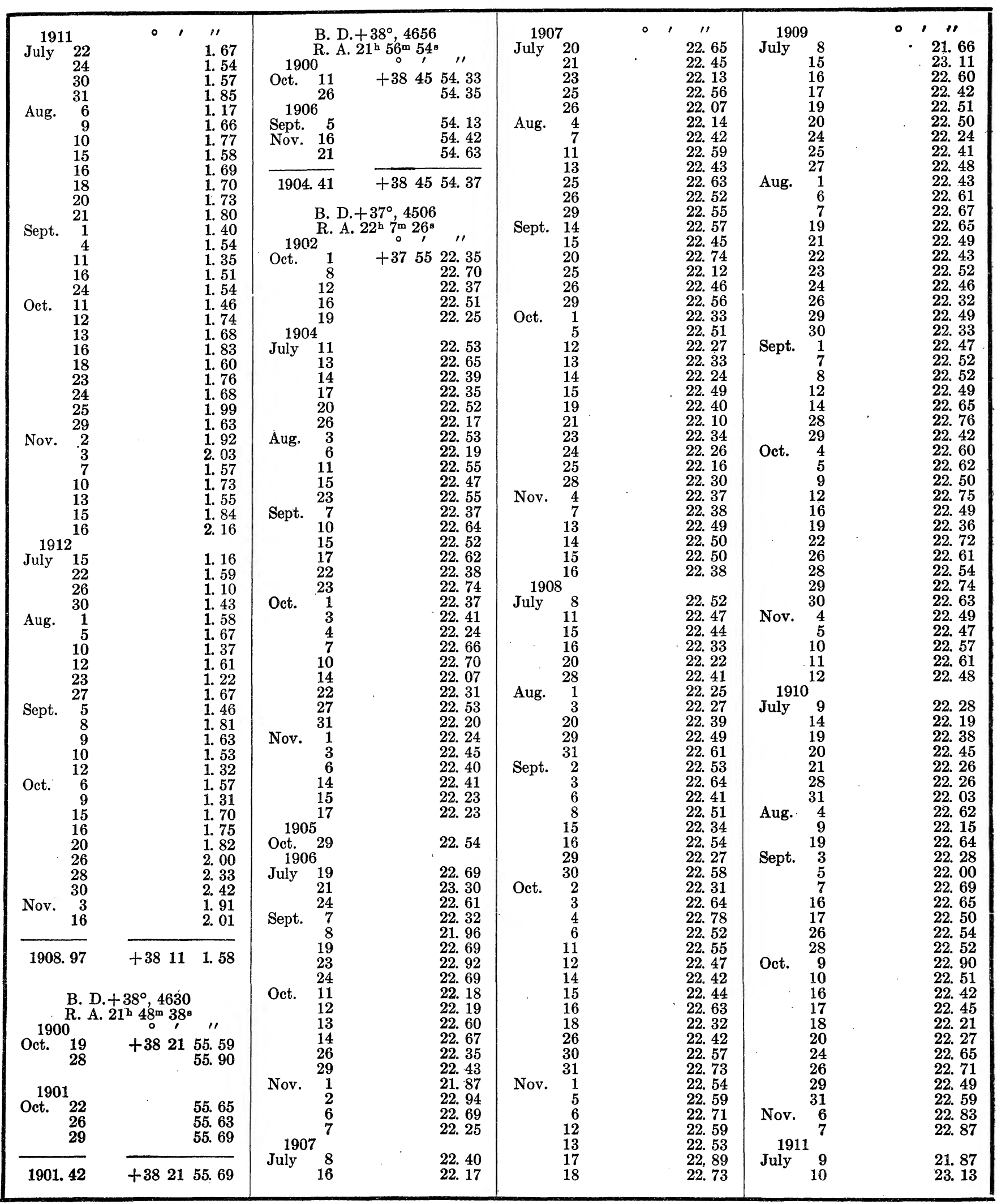




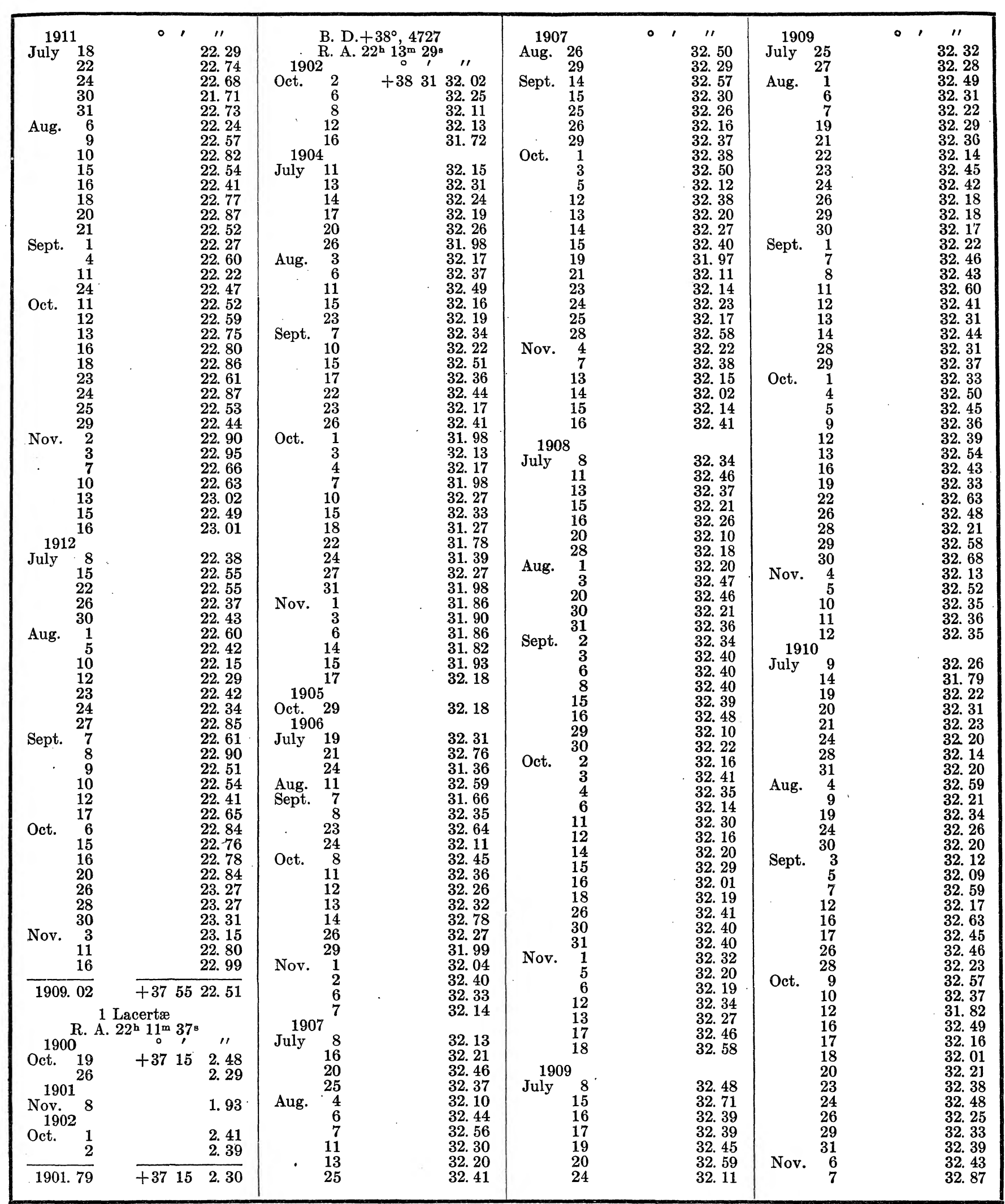




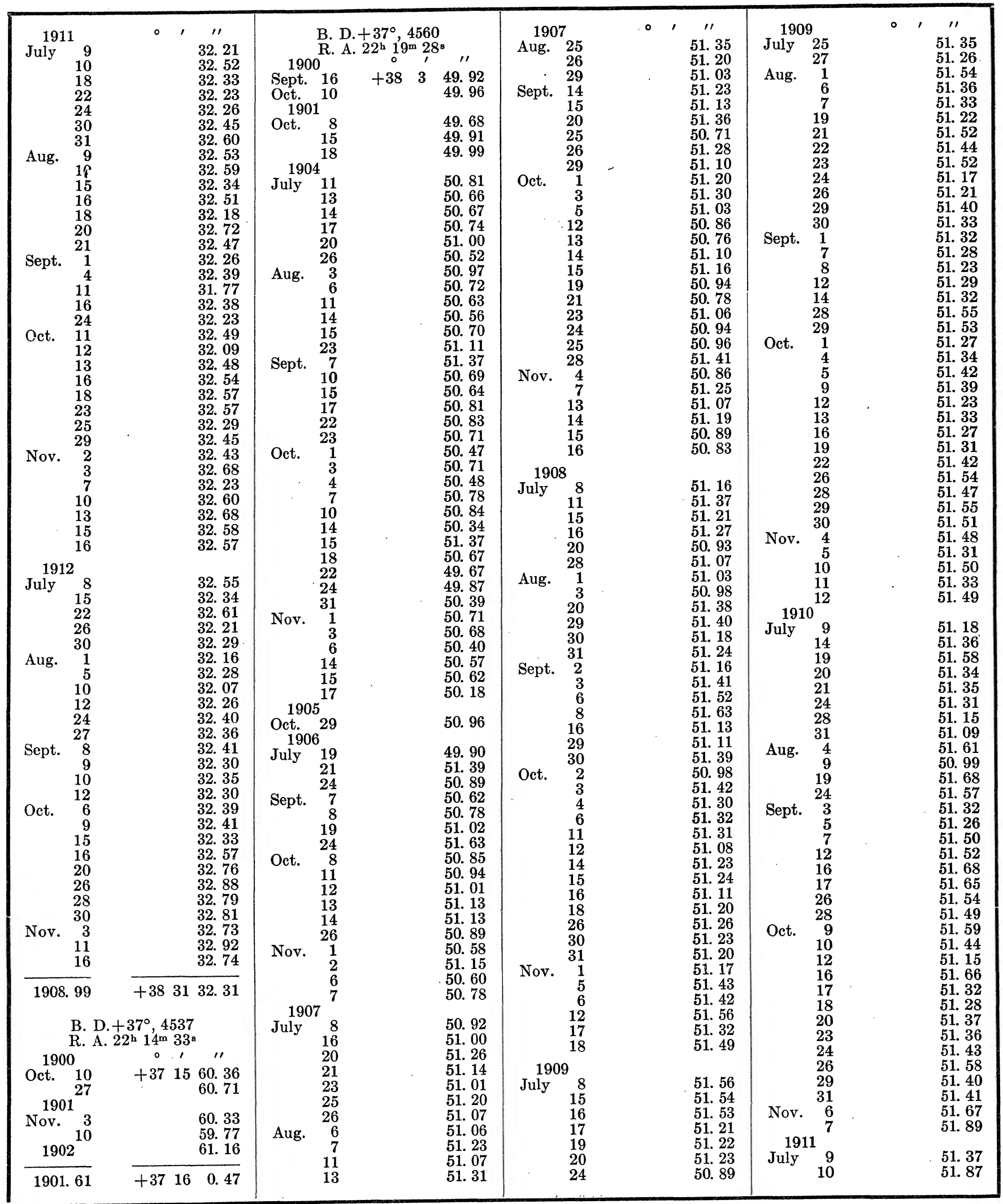




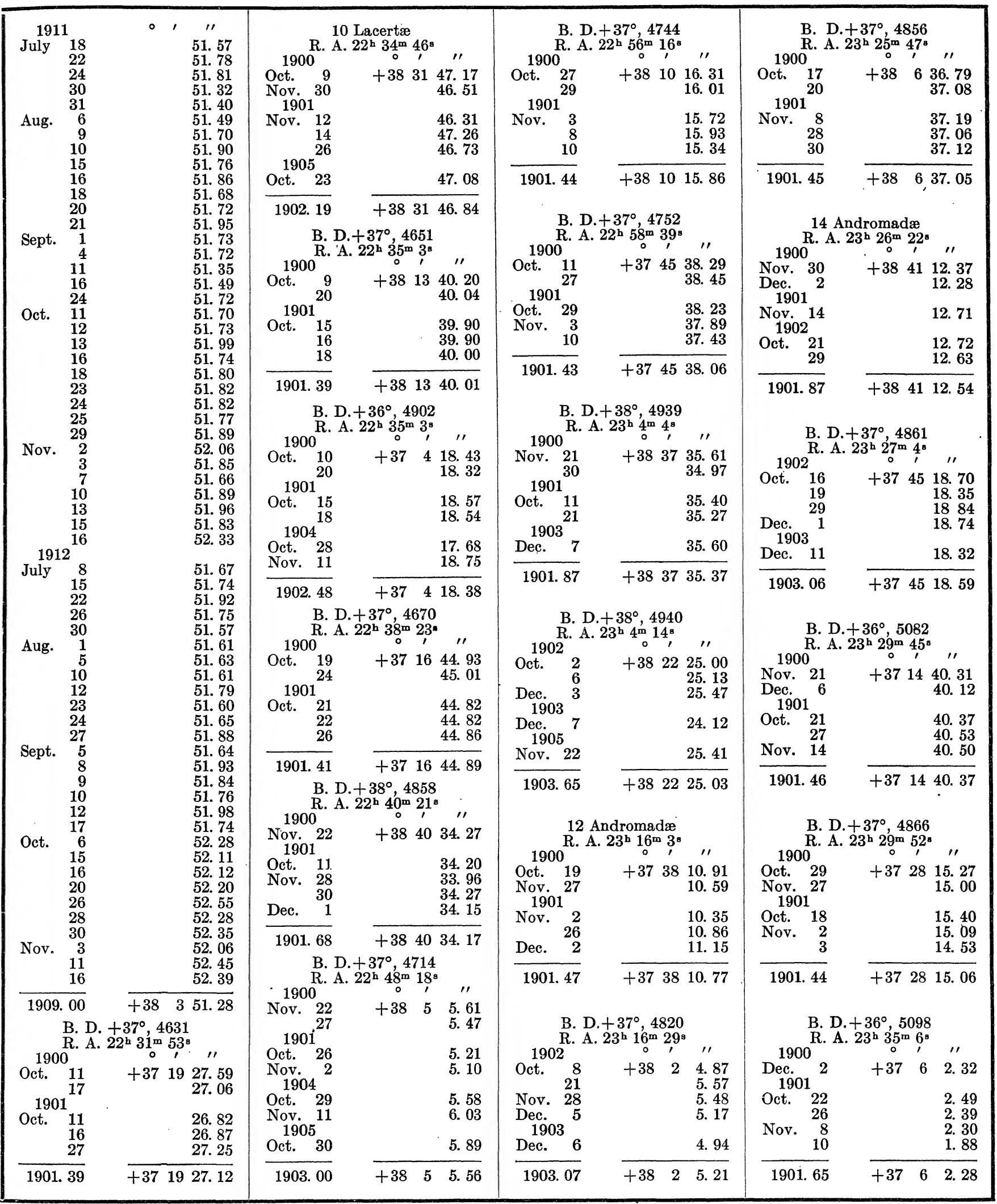


PRIME VERTICAL TRANSIT INSTRUMENT.

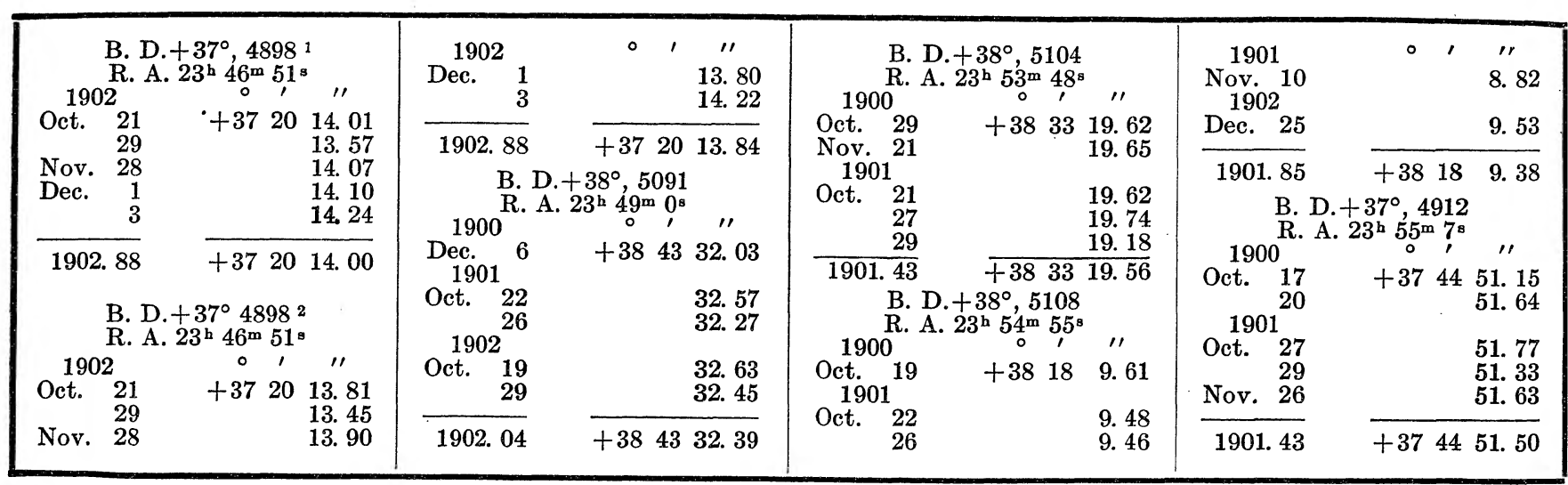

